Article

\title{
Design of Corrosion Protective and Antistatic Hybrid Sol-Gel Coatings on 6XXX AlMgSi Alloys for Aerospace Application
}

\author{
Cecilia Agustín-Sáenz *®D, Patricia Santa Coloma, Francisco J. Fernández-Carretero®, \\ Fabiola Brusciotti and Marta Brizuela \\ TECNALIA, Basque Research and Technology Alliance (BRTA), Mikeletegi Pasealekua 2, \\ 20009 Donostia-San Sebastián, Spain; pasantacol@yahoo.es (P.S.C.); francisco.fernandez@tecnalia.com (F.J.F.-C.); \\ fabiola.brusciotti@tecnalia.com (F.B.); marta.brizuela@tecnalia.com (M.B.) \\ * Correspondence: cecilia.agustin@tecnalia.com; Tel.: +34-946-430-850
}

Received: 3 April 2020; Accepted: 27 April 2020; Published: 30 April 2020

check for updates

\begin{abstract}
An inorganic-organic coating based on glycidyl-functionalized silica and zirconia was synthesized by sol-gel technology to protect three types of AlMgSi (6XXX series) alloys against corrosion in aerospace applications. Different parameters such as the solid content, the organic/inorganic ratio of the sols and the deposition conditions were studied with the aim to achieve a tradeoff between the corrosion protection, antistatic performance and low vacuum-induced outgassing. Those parameters directly influence the thickness and the density of the coatings, and therefore the barrier effect against corrosion and the contact electrical resistance, which are affected in opposite ways. To obtain a low contact electrical resistance, silver nanowires (NW) with a high aspect ratio were loaded in the sol-gel matrix with the aim to create a conductive path through the hybrid coating with a low concentration of NWs. The coatings were adapted for AA6063, AA6061 and AA6082, and they all showed an outstanding anti-corrosion performance in different artificial weathering tests, whereas electrochemical impedance spectroscopy permitted the identification of the most critical parameters affecting water uptake. An antistatic performance was demonstrated by the low contact electrical resistance of the coated AA6061 and AA6063 alloys, although the incorporation of NWs showed a detrimental effect on the corrosion protection compared with the unloaded coating.
\end{abstract}

Keywords: corrosion protection; hybrid sol-gel coating; aerospace; outgassing; AlMgSi; 6XXX

\section{Introduction}

AlMgSi (6XXX series) alloys are widely used as structural materials in the aerospace and automobile industries owing to their favorable strength-to-weight ratio and their relatively high corrosion resistance [1]. Because the level of strength achievable by adding only Si is low, $\mathrm{Mg}$ is also added to improve the strength through the formation of $\beta$-phase $\left(\mathrm{Mg}_{2} \mathrm{Si}\right)$ precipitates. Even higher mechanical properties, strength and ductility of that heat treatable alloys can be obtained by either alloying with a low amount of $\mathrm{Cu}$ or adding an excess amount of $\mathrm{Si}$, considering the stoichiometry of $\mathrm{Mg}_{2} \mathrm{Si}$ precipitates [2]. Depending on the alloying elements and their ratio, AlMgSi alloys have been divided in three groups [3]. The first and second groups (e.g., AA6063 and AA6061 respectively) are alloys with balanced amounts of $\mathrm{Mg}$ and $\mathrm{Si}$. Alloys of the first group contain low weight percentage of $\mathrm{Mg}$ and Si (0.8-1.2\%), while alloys of the second group contain them in a weight percentage $>1.4 \%$ and $\mathrm{Cu}$ is also added to improve the mechanical properties. The alloys of the third group (e.g., AA6082) contain excess of $\mathrm{Si}$, which is also responsible for age hardening (unbalanced alloys). In general, the approaches to improve mechanical properties through microstructural modifications result in 
detrimental changes to corrosion properties. Therefore, the effect of both copper content $[2,4-6]$ and $\mathrm{Si}$ excess [2] on the susceptibility to corrosion resistance have been discussed.

In aerospace applications, these alloys are normally passivated with conversion coatings containing hexavalent chromium, although recently high efforts for its replacement are being performed, resulting in the use of trivalent chromium, silicate, vanadate, molybdate, permanganate and zirconate compounds $[7,8]$. These coatings convert the electrochemically active metal surface to a passive state by forming a mixed metal oxide layer. Organic and hybrid coatings synthesis technologies have also attracted many researchers because of environmental compliance and outstanding corrosion protection of a wide range of metals and alloys. Among them, sol-gel method is a versatile approach for coating material design due to the possibility of combining inorganic and organic moieties covalently bonded through inorganic polycondensation and organic polymerization reactions taking place simultaneously [9].

In the design of parts for aircraft and spacecraft industries, the phenomenon of static electricity must also be considered. The accumulation of extreme static charges on an aircraft, generated by the interaction between the outer surface of the aircraft and external environmental phenomena (air particles, ice, hail, dust, volcanic ash, lightning strike) or triboelectric charging, can lead to failure of parts and eventually to severe explosion or radio communication failure $[10,11]$. The huge current caused by lightning travels through the least resistant parts of the aircraft structure [12]. It is important to create a conductive path of low resistance over the entire aircraft exterior to prevent the lightning charge from attaching to several parts and then arcing or sparking. Surface finish must be also considered. If corrosion protective or decorative coatings are too thick, they may disrupt the conductive path with consequential increasing of surface resistance and risk of greater damage.

High vacuum is another crucial factor when designing materials for space environment, due to the induced material outgassing. Outgassing is referred to as the release of gaseous species from a specimen under high vacuum conditions. Outgassing materials can be harmful to the performance of spacecrafts since expelled gases result in contamination, which indeed can affect the performance of optical instruments, solar cells, thermal control surfaces, ultraviolet astronomy, etc.

In a recent work of the authors [13], a hybrid organic-inorganic sol-gel coating material with anticorrosion performance was developed and applied on zinc coated steel. The sol-gel synthesis was based on the incorporation of organic precursors in an epoxy functionalized-silica-zirconia hybrid matrix. The present work has focused on the improvement and adaptation of the bi-phenol containing sol-gel formulation, which had resulted in the composition with the highest corrosion resistance properties, for providing enhanced corrosion protection on AlMgSi alloys in compliance with aerospace applications. In particular, one alloy of each group has been selected, namely AA6063 from the first group, with low content of $\mathrm{Mg}$ and $\mathrm{Si}$ (tensile strength $245 \mathrm{MPa}$ ), AA6061 from the second group, with medium content of $\mathrm{Mg}$ and $\mathrm{Si}$ and further $\mathrm{Cu}$ addition (tensile strength $\sim 310 \mathrm{MPa}$ ), and AA6082 from the third group, with unbalanced $\mathrm{Si}$ (tensile strength $~ 345 \mathrm{MPa}$ ). AA6061 exhibits high corrosion resistance and excellent extrudability and AA6063 is widely used owing to its extrudability. Recently, AA6061 and AA6063 are being replaced by AA6082 in some aerospace applications due to its higher strength to weight ratio [14]. With the aim to reach a tradeoff between corrosion protection, low electrical resistance, low water uptake and low outgassing, different approaches have been tackled for the three alloys: (i) coating thickness has been studied on AA6061, to obtain the required corrosion protection with the minimum amount of material and ensure low electrical resistance, (ii) equivalent solid concentration and inorganic/organic ratio of sol formulation were adapted to improve AA6082 protection, (iii) the sol-gel matrix was modified with Ag nanowires to create a conductive path and decrease the surface resistance of AA6063. The effect of coating density, thickness and roughness on surface electrical resistance (measured according to MIL-DTL-81706B [15]) and on corrosion performance (evaluated through electrochemical impedance spectroscopy) has been determined. Durability has been assessed, following aerospace industry specifications, through neutral salt spray, thermal cycling and damp heat exposure, in comparison to $\mathrm{Cr}$ VI and Cr III conversion 
coatings. A partial vacuum-induced outgassing of the coatings has been studied according to the ECSS-Q-ST-70-02C standard [16] to check the suitability for space applications.

\section{Materials and Methods}

\subsection{Materials}

$N$-propanol (extra pure, > 99\%) solvent was purchased from Scharlab, S.L. (Sentmenat, Spain), Si alkoxide tetraethyl orthosilicate (TEOS, purity $98 \%$ ) as silica precursor was purchased from Acros Organics (Geel, Belgium) and Si epoxy functionalized-alkoxide glycidoxypropyl trimethoxysilane (GPTMS, purity $>98 \%$ ) as hybrid precursor was purchased from Sigma-Aldrich (St. Louis, MO, USA), as well as the organic precursor bisphenol A (BPA, purity 97\%). All of them were used as received. Sulfuric acid $\left(\mathrm{H}_{2} \mathrm{SO}_{4}\right.$, purity $\left.95-97 \%\right)$ was purchased from Scharlab, S.L. and it was used to prepare a $0.1 \mathrm{M}$ solution in deionized water which worked as catalyst.

Zirconium (IV) n-propoxide (TPOZ, 70\% in n-propanol) was used as zirconia precursor and purchased from Acros Organics; acetyl acetone (AcAc, purity 99\%), used as complexing agent, was provided by Scharlab, S.L., and both were used as received.

Ag nanowires (NW) were purchased from ACS Material, Pasadena, CA, USA, (AgNW, $20 \mathrm{mg} / \mathrm{mL}$ in 1-propanol) and were $50 \mathrm{~nm}$ thick (diameter) and $200 \mu \mathrm{m}$ long.

Solutions of sodium fluorosilicate, 2-(2-butoxyethoxy) ethanol, 4-nonylphenyl-polyethylene glycol and anionic surfactant from Turco Española, S.A. (Barcelona, Spain) were used for preparing alkaline degreasing bath. Solution of sodium bifluoride and ferric sulfate from Turco ${ }^{\circledR}$ as well as nitric acid $\left(\mathrm{HNO}_{3}, 67 \% \mathrm{vol}\right)$ from Sigma-Aldrich were used for preparing acid picking bath.

The Cr VI conversion coating, Alodine 1200S, was purchase from Henkel (Germany), while the Cr III conversion coating, Surtec 650, was purchase from SurTec (Bensheim, Germany).

The substrates used were 1-mm thick sheet of commercial cold-rolled wrought $6082 \mathrm{~T} 6 \mathrm{Al}$ alloy; 1-mm thick sheet of commercial cold-rolled wrought $6061 \mathrm{~T} 6 \mathrm{Al}$ alloy; and 5-mm thick sheet of commercial cold-rolled wrought $6063 \mathrm{~T} 6 \mathrm{Al}$ alloy. These aluminum sheets were provided by Alcupla (Valencia, Spain), Iberia (Madrid, Spain) and Lanema de Aluminios y Plásticos (Ajalvir, Spain), respectively, and their chemical composition is shown in Table 1.

Table 1. Chemical nominal composition (wt \%) of AlMgSi alloys.

\begin{tabular}{cccccccccc}
\hline AlMgSi Alloy & Si & Fe & Cu & Mn & Mg & Cr & Zn & Ti & Al \\
\hline 6082 T6 & 0.90 & 0.43 & 0.09 & 0.45 & 0.90 & 0.03 & 0.09 & 0.03 & Balance \\
6061 T6 & 0.68 & 0.36 & 0.18 & 0.08 & 1.1 & 0.17 & $<0.02$ & $<0.03$ & Balance \\
6063 T6 & 0.46 & 0.23 & $<0.05$ & 0.05 & 0.52 & $<0.05$ & 0.03 & $<0.03$ & Balance \\
\hline
\end{tabular}

\subsection{Preparation of Sols}

The preparation of the sols was based on the admixture and formation of two stable and homogeneous parts, the first one obtained by the admixture of silica precursor TEOS, Si epoxy functionalised-alkoxide GPTMS and organic precursor BPA. The second one was obtained by the admixture of zirconia precursor TPOZ in n-propanol solvent, complexed with AcAc.

In the first part, TEOS, GPTMS and BPA were mixed in n-propanol media and hydrolysed employing an aqueous $0.1 \mathrm{M} \mathrm{H}_{2} \mathrm{SO}_{4}$ solution. The resultant solution was stirred during $3 \mathrm{~h}$ at $40^{\circ} \mathrm{C}$ (Si part).

Simultaneously, n-propanol was placed in a cell in which air was replaced by Ar to achieve an inert humidity-free atmosphere. Then, TPOZ and AcAc were introduced in the cell and stirred during $1 \mathrm{~h}$ in order to form the chelate to control the hydrolysis/condensation reactions. After that, a mixture of $0.1 \mathrm{M} \mathrm{H}_{2} \mathrm{SO}_{4}$ solution and n-propanol were added to the solution and kept stirred for $24 \mathrm{~h}$ (Zr part).

After $24 \mathrm{~h}$, both $\mathrm{Si}$ and $\mathrm{Zr}$ parts were transparent and had completely reacted. They were slowly admixed together at an equivalent $\mathrm{Si} / \mathrm{Zr}$ molar ratio of 5 thus obtaining the final sol ready for use. 
Three different matrix sols were considered in which the precursors were studied in varied ratios. The first one (Sol A) was the outcome of previous work [13], the second one (Sol AC) was formulated with $1 / 3$ less of propanol in the $\mathrm{Zr}$ part, in order to obtain a sol with higher solid content and to deposit thicker and denser layers. The third sol formulation ( $\mathrm{Sol} \mathrm{B}$ ) was designed by doubling the GPTMS: TEOS mol ratio, with consequently doubled mole of BPA. Furthermore, in order to maintain the ratio $\mathrm{Si} / \mathrm{Zr}$ of the final formulation, mole of TPOZ was adjusted (and consequently mole of AcAc).

Table 2 shows the molar ratio of precursors and components of the three formulations studied.

Sol A with incorporation of AgNW was also prepared. They were diluted in the propanol used from the beginning of the synthesis, and their concentration in the resultant so-called Sol A-AgNW was $0.5 \%$ wt.

Table 2. Molar ratio of components used for preparing sols with and without organic precursors.

\begin{tabular}{ccc}
\hline & Si Part & Zr Part \\
\hline \multirow{2}{*}{ Sol A } & TEOS/GPTMS/BPA/n-propanol/ $\mathrm{H}_{2} \mathrm{SO}_{4} 0.1 \mathrm{M}$ & TPOZ/AcAc/n-propanol/ $\mathrm{H}_{2} \mathrm{SO}_{4} 0.1 \mathrm{M}$ \\
& Molar ratio 1:1:0.5:2:4 & Molar ratio 1:1.4:16:3 \\
\hline \multirow{2}{*}{ Sol AC } & TEOS/GPTMS/BPA/n-propanol/ $\mathrm{H}_{2} \mathrm{SO}_{4} 0.1 \mathrm{M}$ & $\mathrm{TPOZ} / \mathrm{AcAc} /$ n-propanol/ $/ \mathrm{H}_{2} \mathrm{SO}_{4} 0.1 \mathrm{M}$ \\
& Molar ratio 1:1:0.5:2:4 & Molar ratio 1:1.4:5.4:3 \\
\hline \multirow{2}{*}{ Sol B } & TEOS/GPTMS/BPA/n-propanol/ $/ \mathrm{H}_{2} \mathrm{SO}_{4} 0.1 \mathrm{M}$ & $\mathrm{TPOZ} /$ AcAc/n-propanol/ $\mathrm{H}_{2} \mathrm{SO}_{4} 0.1 \mathrm{M}$ \\
& Molar ratio 1:2:1:2:6 & Molar ratio 1:1.4:16:3 \\
\hline
\end{tabular}

\subsection{Substrate Preparation and Coating Deposition}

The coatings were deposited on flat plates of AA6082, AA6061 and AA6063, with $125 \mathrm{~mm} \times 75 \mathrm{~mm}$ dimension. The plates were first manually degreased with acetone spraying and then cleaned by immersion $(15 \mathrm{~min})$ in an alkaline bath at $50{ }^{\circ} \mathrm{C}$, consisting of a solution of $\mathrm{Na}_{2} \mathrm{SiF}_{6}(<2.25 \mathrm{~g} / \mathrm{L})$, 2-(2-butoxyethoxy) ethanol (1.2-2.3 g/L), 4-nonylphenyl-polyethylene glycol $(<0.012 \mathrm{~g} / \mathrm{L})$ and anionic surfactant $(<4.5 \mathrm{~g} / \mathrm{L})$, in deionized water. The plates were then rinsed in deionized water and deoxidized in an acid bath containing $\mathrm{NaHF}_{2}(<12 \mathrm{~g} / \mathrm{L}), \mathrm{Fe}_{2}\left(\mathrm{SO}_{4}\right)_{3}(60-108 \mathrm{~g} / \mathrm{L})$ and $\mathrm{HNO}_{3}(15.35 \mathrm{~g} / \mathrm{L})$ at room temperature during $5 \mathrm{~min}$ and then rinsed in deionized water, sprayed with ethanol and dried with compressed air.

At this point, the plates were introduced in the different prepared sols and withdrawn at controlled rates of 5,15 and $35 \mathrm{~cm} / \mathrm{min}$. Curing was carried out by thermal treatment in an oven at $180^{\circ} \mathrm{C}$ for $1 \mathrm{~h}$. Coatings were denominated A-coatings, AgNW-coatings, AC-coatings and B-coatings, depending on the sol formulation, as indicated in Table 3. Also, the number in the subscript refers to the dip-coating withdrawal rate.

Table 3. Coatings deposited and studied on each AlMgSi alloy.

\begin{tabular}{cccc}
\hline AlMgSi Alloy & Sol Formulation & Withdrawal Rate $\mathbf{( c m} / \mathbf{m i n})$ & Coating \\
\hline \multirow{2}{*}{ AA6082 T6 } & Sol A & 5 & $\mathrm{~A}_{5}$-coating \\
& \multirow{2}{*}{ Sol AC } & 15 & $\mathrm{~A}_{15}$-coating \\
& \multirow{2}{*}{ Sol B } & 5 & $\mathrm{AC}_{5}$-coating \\
& & 15 & $\mathrm{AC}_{15}$-coating \\
& \multirow{2}{*}{ Sol A } & 5 & $\mathrm{~B}_{5}$-coating \\
AA6061 T6 & & 15 & $\mathrm{~B}_{15}$-coating \\
& & 5 & $\mathrm{~A}_{5}$-coating \\
& \multirow{2}{*}{ Sol A } & 15 & $\mathrm{~A}_{15}$-coating \\
AA6063 T6 & Sol A-AgNW & 55 & $\mathrm{~A}_{35}$-coating \\
& & 15 & $\mathrm{~A}_{5}$-coating \\
& & 5 & $\mathrm{~A}_{15}$-coating \\
\end{tabular}


Commercial Cr VI and Cr III conversion coatings (Alodine 1200 S and Surtec 650, respectively) were applied on AA6063 and AA6082 as reference. Both conversion coatings were applied on the aluminum alloys plates according to MIL-DTL-5541F [17] by a company accredited for aerospace applications.

\subsection{Characterization}

The stability of final liquid sols was evaluated by viscosity measurements during 6 months after preparation. The kinematic viscosity of sols was measured at $20^{\circ} \mathrm{C}$ by means of a Ubbelohde viscosimeter, in which the liquid flows through a capillary tube driven by gravity. Capillary tube type $1 \mathrm{C}$ was used for sols, with kinematic viscosity between 6 and $30 \mathrm{cSt}$. Three repetitions were taken for each sample. Dynamic viscosity was obtained by multiplying mean kinematic viscosity by the density previously determined with a pycnometer.

The coating thickness was measured using a contact profilometer Dektak 150 (Veeco, Munich, Germany) on soda lime samples, which were coated by dipping at 2, 5, 15 and $35 \mathrm{~cm} / \mathrm{min}$ in the same conditions as the metal plates. The coatings were scratched with a pin before the curing cycle, to remove the coating in that specific area. After thermal treatment, five scans were taken crossing the scratch along $50 \mathrm{~mm}$. Thickness was determined by measurement of the step height. Mean value of the five scans was calculated.

The morphology of the coatings was examined by scanning electron microscopy (SEM) using a low-vacuum JEOL JSM 5910 LV equipment (JEOL Ltd., Tokio, Japan). Secondary electron and backscattered electron images were collected at $20 \mathrm{kV}$. Analysis of the top-view and cross-section was performed. The mean value of the coating thickness was also calculated by image analysis of cross-section images.

Roughness measurements were performed using the contact profilometer described above, on bare and sol-gel coated AlMgSi alloys, according to ISO 4288 [18]. Five 4.8-mm length scans were taken on each sample using a $2-\mu \mathrm{m}$ radius stylus, $1 \mathrm{mg}$ force and lengthwise resolution of $0.32 \mu \mathrm{m}$. Arithmetic average roughness, $R_{a}$, was calculated from the central $4 \mathrm{~mm}$ of the scan using short and long pass filter cutoff of $800 \mu \mathrm{m}$. Maximum peak $\left(R_{p}\right)$ and valley $\left(R_{v}\right)$ correspond to the highest or lowest peak of the profile roughness above or below the mean line. Mean $R_{a}, R_{p}$ and $R_{v}$ values were calculated from the five scans performed on each sample.

The coating chemical composition was characterized by X-ray photoelectron spectroscopy (XPS). The XPS analyses were performed in a SPECS Sage HR 100 spectrometer with a non-monochromatic $\mathrm{X}$-ray source (Magnesium $\mathrm{K} \alpha$ line of $1253.6 \mathrm{eV}$ energy and $250 \mathrm{~W}$ ), placed perpendicular to the analyzer axis and calibrated using the $3 \mathrm{~d} 5 / 2$ line of $\mathrm{Ag}$ with a full width at a half maximum (FWHM) of $1.1 \mathrm{eV}$. The selected resolution was 30 and $15 \mathrm{eV}$ of pass energy and 0.5 and $0.15 \mathrm{eV} / \mathrm{step}$ for the general survey and for the high-resolution spectra, respectively. The samples were measured after $3 \mathrm{~min}$ of etching with $\mathrm{Ar}^{+}$ions at a $3 \mathrm{kV}$ beam energy. The relative chemical composition was determined by calculations using the Casa XPS V2.3.15dev87 software, based on the relative areas and sensitivity factors of the $\mathrm{Zr} 3 \mathrm{~d}, \mathrm{Si} 2 \mathrm{p}, \mathrm{C}$ 1s and $\mathrm{O} 1$ s higher resolution spectra.

The surface electrical resistance was measured before and after exposure to neutral salt spray test (NSST), based on the method described in the MIL-DTL-81706B standard [15]. The coated aluminum alloys were placed in between two contacting copper electrodes under an applied electrode pressure of $14 \mathrm{~kg} / \mathrm{cm}^{2}$. The contact area of the upper electrode was $6.54 \mathrm{~cm}^{2}$ and that of the lower electrode was $19.8 \mathrm{~cm}^{2}$, both were mirror-polished. Six measurements were performed on each $125 \times 75 \mathrm{~mm}$ plate. The measurements were carried out in DC by using a micro-ohmeter Megger DLRO 10x with a maximum resolution of $0.1 \pm 0.2 \% \mu \Omega$ in the range of $1.9999 \mathrm{~m} \Omega$. The direct value of resistance was obtained from the measurement. The resistance of the system without sample was obtained at the beginning of the experiment. The contact electrical resistance was calculated by subtracting the system resistance and by dividing by the cross-section of the upper electrode.

Electrochemical impedance spectroscopy (EIS) was employed to monitor corrosion performance of bare and coated AlMgSi alloys immersed in $3.5 \% \mathrm{NaCl}$ solution for $72 \mathrm{~h}$. The electrochemical cell 
was composed by three electrodes consisting of working electrode $\left(9.62 \mathrm{~cm}^{2}\right.$ exposed area), saturated $\mathrm{Ag} / \mathrm{AgCl} / \mathrm{KCl}$ reference electrode and $\mathrm{Pt}$ wire counter electrode. EIS measurements were carried out at the open circuit potential (OCP), using an Autolab PG-STAT 128N potentiostat (Methrom, Herisau Switzerland). equipped with a frequency response analyser module. Impedance data were obtained with a sinusoidal perturbation of $15 \mathrm{mV}$ amplitude (root mean square, RMS) over the frequency range from $10^{5} \mathrm{~Hz}$ to $10^{-2} \mathrm{~Hz}$. Two repetitions were performed on duplicate samples.

The corrosion performance by artificial weathering of the bare and coated aluminum alloys was evaluated in neutral salt spray test, damp heat test (DHT), and thermal cycling test (TCT). NSST was carried out in a salt spray chamber C\&W Model SF/1000/CCT. The test conditions were in accordance with ASTM B117, which maintained a salt spray fog environment coming from a $5 \% \mathrm{NaCl}$ solution at $35^{\circ} \mathrm{C}$. Plates were exposed supported at $6^{\circ}$ from the vertical in accordance with aeronautic specifications (MIL-DTL-5541F [17] and MIL-DTL-81706B [15]) up to $168 \mathrm{~h}$. The DHT test consisted in applying a temperature of $40{ }^{\circ} \mathrm{C}$ with $100 \%$ humidity to the coated samples. The test was performed for $800 \mathrm{~h}$ in a humidity chamber OMI Model HK-84. Periodically, the samples surface was visually inspected and recorded by photographs. The TCT consisted in the application of 100 cycles with a thermal profile based on ECSS-Q-ST-70-04C specification [19]. Thermal cycles were performed between $-70^{\circ} \mathrm{C}$ and $100{ }^{\circ} \mathrm{C}$, with dwell times of $15 \mathrm{~min}$ and cooling and heating rates of $3.5^{\circ} \mathrm{C} / \mathrm{min}$ and $6{ }^{\circ} \mathrm{C} / \mathrm{min}$, respectively, using a CTS Model CSR-60/500 thermal chamber. After the 100-cycle test, the samples were subjected to the NSST for $168 \mathrm{~h}$ at the conditions described above. Each sample was tested in triplicate.

Vacuum-induced outgassing measurements were performed at the Spanish National Institute for Aerospace Technology (INTA) following the indications of the ECSS-Q-ST-70-02C specification [16]. The studied sols were deposited at $15 \mathrm{~cm} / \mathrm{min}$ on aluminum foils at the same conditions as the metal plates. Coated aluminum foils were rolled up to attain a mass of coating material between 100 and $300 \mathrm{mg}$, and then put in the chamber. The samples were conditioned at $22 \pm 3^{\circ} \mathrm{C}$ and $55 \pm 10 \%$ relative humidity for $24 \mathrm{~h}$. Then, the test was performed during $24 \mathrm{~h}$ in the chamber at a vacuum pressure between $10^{-4}-10^{-5} \mathrm{~Pa}$ and a constant temperature of $125^{\circ} \mathrm{C}$, while the temperature of the collector plate was maintained at $25^{\circ} \mathrm{C}$. Then, the samples were post-conditioned at $22 \pm 3{ }^{\circ} \mathrm{C}$ and $55 \pm 10 \% \mathrm{HR}$ for $24 \mathrm{~h}$. Each sample was tested in triplicate and the mean value was calculated. The materials found on the collector plates were analyzed by FTIR.

\section{Results and Discussion}

\subsection{Effect of Solid Content and Organic/Inorganic Ratio in Viscosity and Thickness}

Both the viscosity of the sol and the withdrawal rate have a direct influence on dragging force during the withdrawal step of a specimen from a sol and they are highly important parameters for determining the thickness of a coating deposited by dip-coating method [20]. Therefore, the viscosity of the hybrid sol-gel formulations was studied with time, coupled to the thickness of the derived coatings for four withdrawal rates. Viscosity evolution measurements along 6 months of Sol A was previously studied [13], and it was shown that the presence of BPA organic precursor contributed to give stability to the sol, in comparison to sols with another or without organic precursor. In this work, the two formulations prepared to form denser coatings were studied and compared. Figure 1a shows the evolution of viscosity along 6 months of the sols A, AC and B, while thickness values of the coatings deposited with the three sols at different aging times are depicted respectively in Figure 1b-d.

Baseline Sol A exhibited the lowest viscosity value, $9.4 \mathrm{mPa} \cdot \mathrm{s}$, while concentrated Sol AC showed $14.1 \mathrm{mPa} \cdot \mathrm{s}$. Sol B with higher ratio of organic precursor, showed the highest initial value, $17.1 \mathrm{mPa} \cdot \mathrm{s}$.

The evolution of viscosity with time was different for each sol. As it was observed in previous work [13], the presence of BPA in the epoxy-silica-zirconia sol matrix improved viscosity stability with time, which is crucial for pot life extension. The three sols studied here presented different viscosity behaviors. With its low solid concentration, the viscosity of Sol A doubled after 3 months of aging 
and it stayed constant during 6 months at a value $22 \mathrm{MPa} \cdot s$. However, the viscosity evolution of high concentrated Sol AC increased linearly and abruptly with aging time. Although starting at lower values, it went higher than the one of Sol B after one month. After 6 months, the viscosity of Sol AC reached more than $100 \mathrm{MPa} \cdot \mathrm{s}$. For Sol B, with double molar ratio of GPTMS and BPA, the viscosity presented a similar and parallel behavior to Sol A, reaching $\sim 40 \mathrm{MPa} \cdot \mathrm{s}$ after 6 months of aging.

In the light of this outcome, the viscosity evolution of these epoxy-silica-zirconia matrixes with BPA organic precursor seemed to be dependent on the equivalent concentration but also on the organic/inorganic ratio since Sol B, highly concentrated but with double molar ratio of BPA, resulted in a more stable sol than Sol AC.

Such behavior of sol viscosities led to a broad spread of thickness values for the derived coatings as shown in Figure $1 b-d$ in which the thickness of the coatings prepared with each sol, freshly prepared and after aging for 1, 3 and 6 months, is presented as function of the withdrawal rate. As expected, thickness of deposited coatings increased linearly with withdrawal rate since the dragging force is proportional to both viscosity of sol and withdrawal rate. This is the general behavior for these systems when located in the dragging regime of deposition that corresponds to this relatively high range of speed [21]. The thickness of the coatings prepared with fresh sols at a withdrawal rate in the range 2-35 $\mathrm{cm} / \mathrm{min}$, were in the range 1.3-4.3 $\mu \mathrm{m}$ for Sol A, 1.9-6.4 $\mu \mathrm{m}$ for Sol AC and 1.8-6.7 $\mu \mathrm{m}$ for Sol B. These values were in agreement with the relative viscosity values obtained for the corresponding sols.

The coating thickness also increased as a function of sol aging time, as a consequence of the viscosity increase. The thickest coatings were thus obtained with the concentrated Sol AC. After 6 months of aging, crack-free coatings were only obtained at lower withdrawal rates.
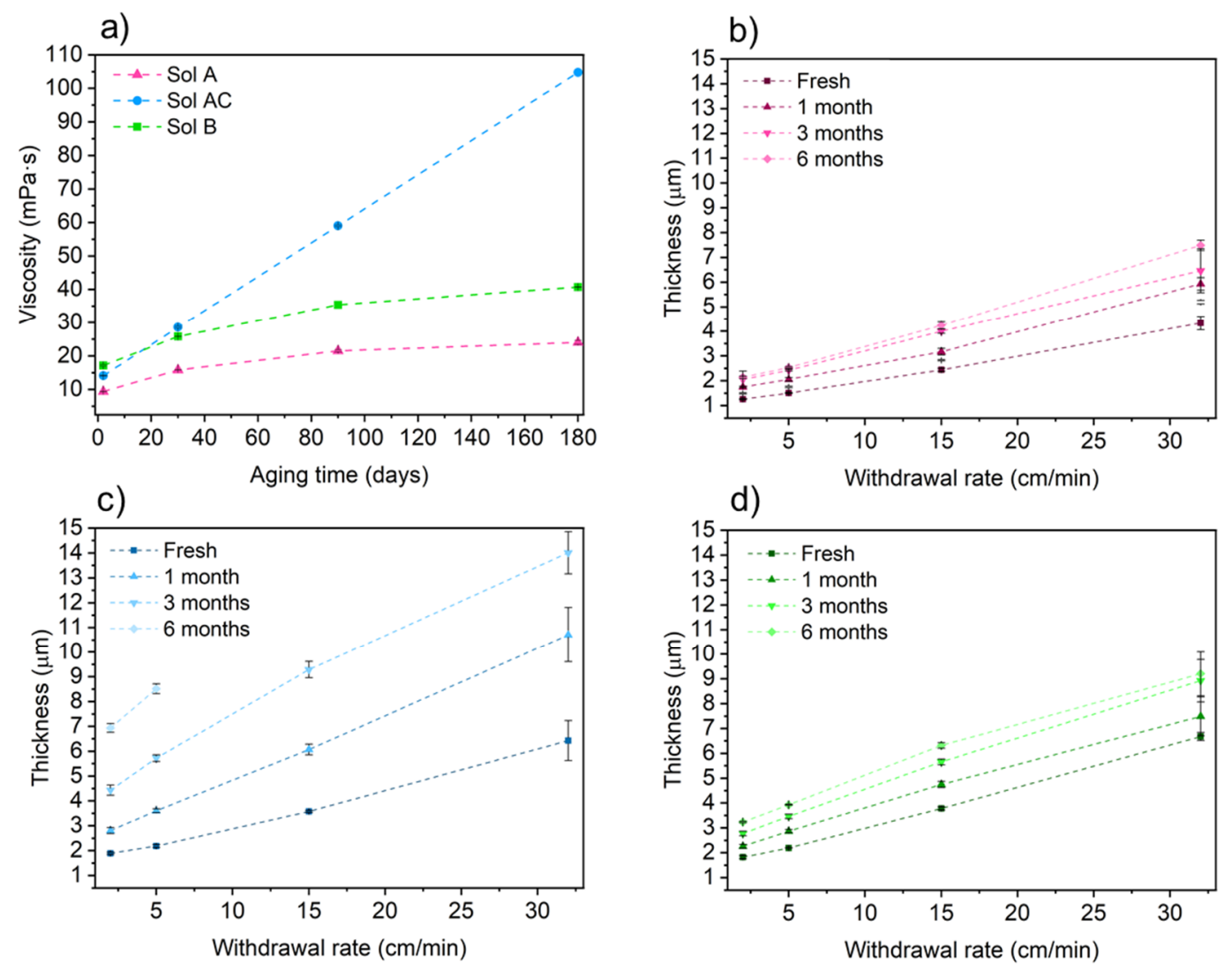

Figure 1. (a) Viscosity evolution of investigated sols and (b-d) thickness of coatings derived from (b) Sol A, (c) Sol AC and (d) Sol B at several withdrawal rates. (Viscosity $\pm 0.5 \mathrm{mPa} \cdot \mathrm{s}$ ).

The thickness of the coatings prepared with Sol A and deposited on aluminum alloys were obtained from analysis of the cross-section SEM images (see Figure 2). The thickness of the coatings 
on AA6061 varied from 1.5 to $3.2 \mu \mathrm{m}$ depending on the withdrawal speed $(5,15$ and $35 \mathrm{~cm} / \mathrm{min})$ and the values were consistent with those obtained for the same coatings deposited on smooth glass and measured by contact profilometer. In a similar way, the thicknesses of coatings derived from Sol A, high-concentrated Sol AC and high-organic/inorganic ratio Sol B, all deposited at $15 \mathrm{~cm} / \mathrm{min}$ on AA6082, were $\sim 2.4, \sim 4$ and $\sim 4.4 \mu \mathrm{m}$, respectively, also consistent with the values obtained on smooth glass by profilometry.

In this work, the control on coating thickness was crucial due to the relevance of this feature on corrosion protection and contact electrical resistance of coated aluminum alloys. A priori, the densest coatings with the highest thickness would permit to achieve better protection properties at the expense of a high contact electrical resistance. It is necessary to reach a tradeoff between these properties in order to fulfill the aerospace requirements.

\subsection{Coating Composition, Appearance and Roughness}

All the sols formed highly adherent and crack-free coatings on the aluminum alloys after the thermal treatment, as observed in the top-view and cross-section images in Figures 2 and 3. In the top-view analysis, the parallel lines coming from the deformation of the substrate during the cold rolling process were visible, due to the thin nature of the coating.
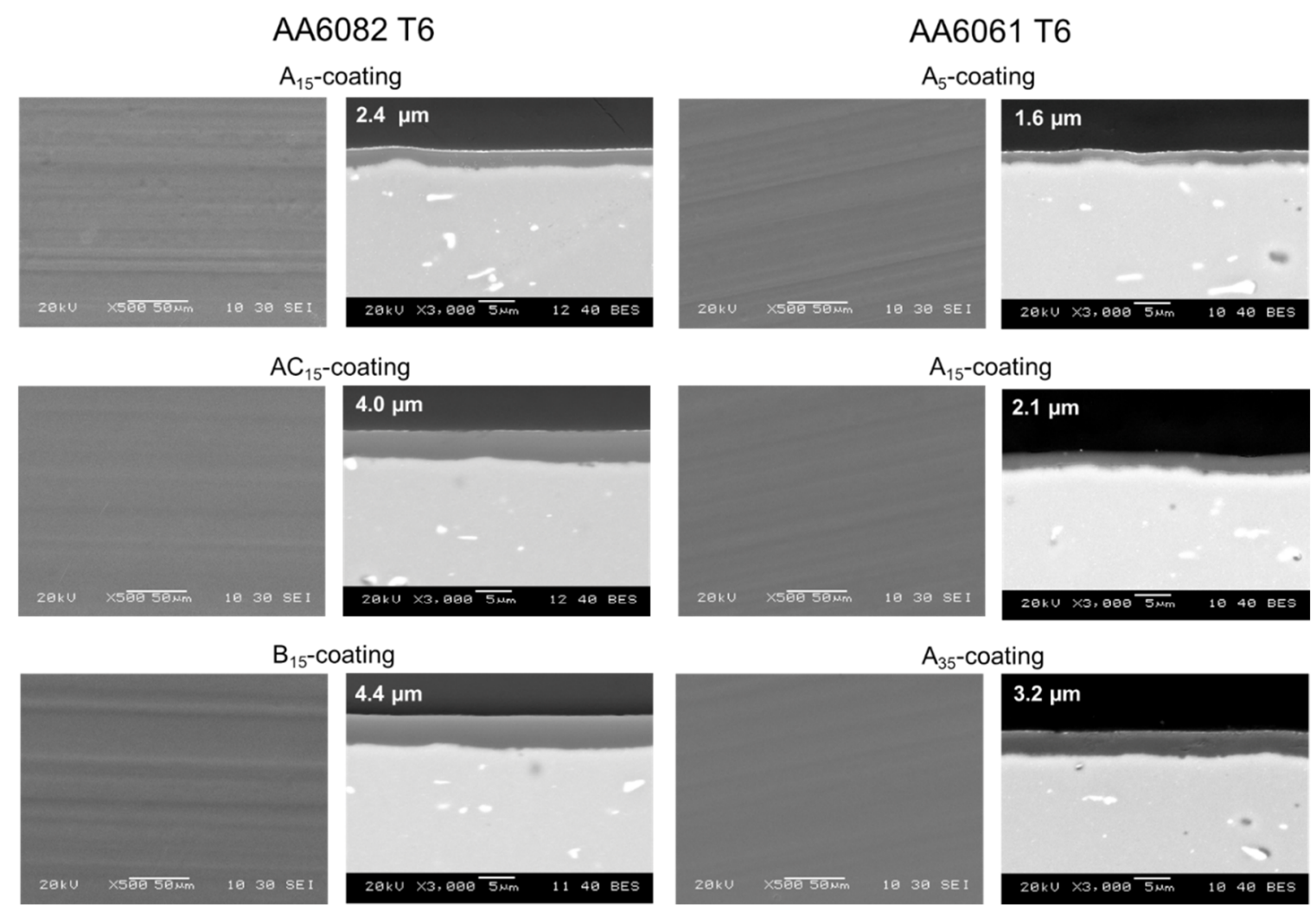

Figure 2. Top-view and cross-section SEM images of coated AA6082 T6 and AA6061 T6.

The roughness of uncoated, acid etched, and sol-gel coated aluminum surfaces was measured. It was observed (Figure 4) that the roughness and profile of the uncoated surfaces differed between the three aluminum substrates. AA6082 presented the highest $R_{a}$ value, $\sim 500 \mathrm{~nm}$, roughness of AA6061 was $R_{a} \sim 320 \mathrm{~nm}$ and AA6063 displayed $R_{a} \sim 280 \mathrm{~nm}$. However, as noticed in Figure 4a, while the profiles of AA6082 and AA6061 presented peaks and valleys of the same magnitude, $R_{p} \sim$ 1400 and $\mathrm{R}_{\mathrm{V}} \sim 1100 \mathrm{~nm}$, AA6063 displayed deep valleys of $\sim 3200 \mathrm{~nm}$. After etching treatment, the surface roughness slightly diminished for AA6082 $\left(\mathrm{R}_{\mathrm{a}} \sim 480 \mathrm{~nm}\right)$ and for AA6061 $\left(\mathrm{R}_{\mathrm{a}} \sim 270 \mathrm{~nm}\right)$, composed by peaks and valleys of the same height and depth $\left(R_{p} \sim 1200\right.$ and $\left.R_{v} \sim 900 \mathrm{~nm}\right)$. However, 
the etching treatment varied the profile of AA6063 as the etched surface displayed more valleys of $R_{\mathrm{v}} \sim 3200 \mathrm{~nm}$ and the average roughness $\mathrm{R}_{\mathrm{a}}$ increased up to $\sim 430 \mathrm{~nm}$. The coatings deposited on such alloys contributed to level their surface (Figure 4c), thus reducing the average roughness as coating thickness increased, promoted either by increasing solid concentration and organic/inorganic ratio of sols deposited at similar rates on AA6082 or by increasing rate during withdrawal step from a given sol as observed for AA6061 and AA6063. The lowest roughness value of a coated aluminum was around $100 \mathrm{~nm}$ for the particular case of AA6061 coated with Sol A at $35 \mathrm{~cm} / \mathrm{min}$.
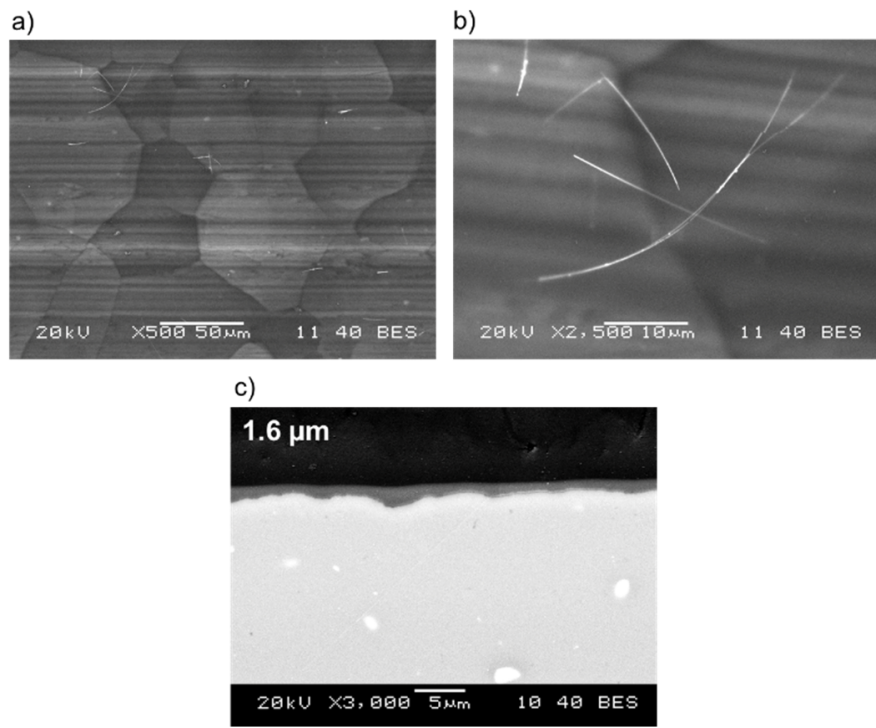

Figure 3. (a,b) Top-view and (c) cross-section SEM images of coating deposited at $5 \mathrm{~cm} / \mathrm{min}$ from Sol A loaded with $0.5 \%$ wt Ag NW, on AA6063 T6.

a)
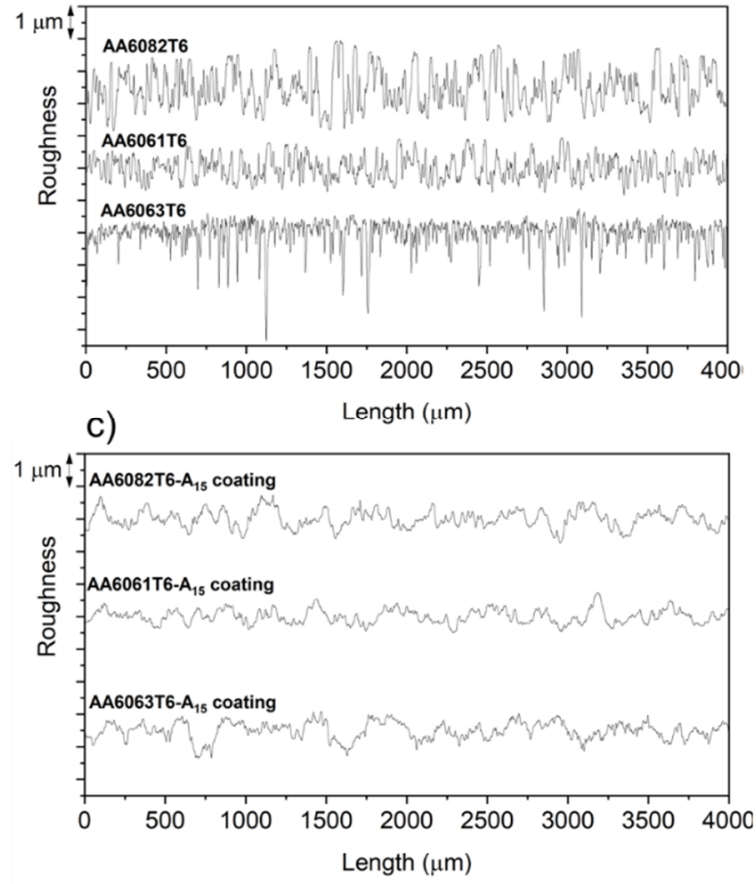

b)

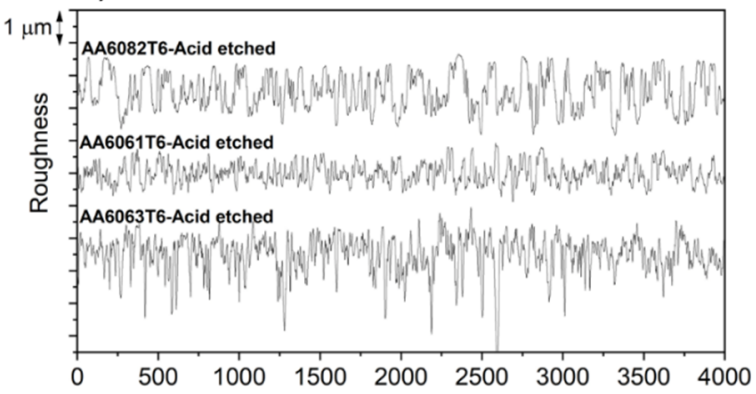

d)

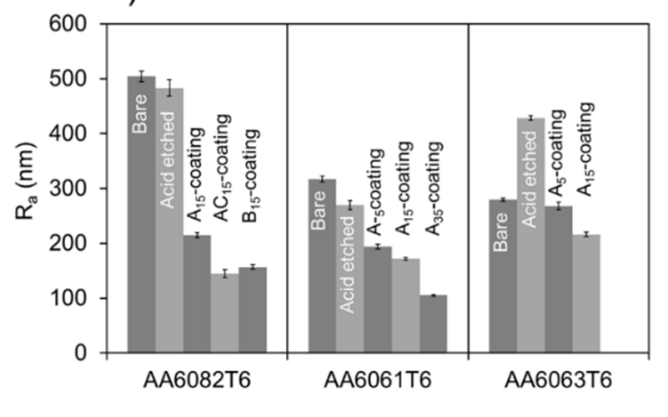

Figure 4. Surface profile of (a) raw, (b) acid etched, (c) A-coated at $15 \mathrm{~cm} / \mathrm{min}$ AlMgSi alloys and (d) average roughness $R_{a}$. 
The coating composition was analyzed by XPS spectroscopy. The high-resolution XPS spectra of $\mathrm{O} 1 \mathrm{~s}, \mathrm{C} 1 \mathrm{~s}, \mathrm{Zr} 3 \mathrm{~d}$, and Si 2p corresponding to A- and B-coatings are presented in Figure 5. Through their analysis, it was possible to determine the accurate peak positions and associate them to $\mathrm{ZrO}_{2}$, sub-stoichiometric $\mathrm{SiO}_{\mathrm{x}}$ bonds, $\mathrm{C}-\mathrm{C}, \mathrm{C}-\mathrm{O}$ and $\mathrm{C}=\mathrm{C}$ bonds. Table 4 collects the atomic percentage of each element in the coating materials derived from sols $\mathrm{A}$ and $\mathrm{B}$ as well as semi-quantitatively estimation of the stoichiometry of the $\mathrm{Zr}$ and $\mathrm{Si}$ oxides. In both materials, the silicon oxide lacked oxygen in a major proportion than the zirconium oxide, as explained in previous recent work [13]. On the other hand, the analysis verified that $\mathrm{Si} / \mathrm{Zr}$ ratio was equal to 5 in both coatings and confirmed the higher quantity of carbon in B-coating, coming from its higher organic/inorganic ratio compared to A-coating.

Table 4. Atomic percentage of $\mathrm{Zr}, \mathrm{Si}, \mathrm{C}$ and $\mathrm{O}$ in the materials derived from sols $\mathrm{A}$ and $\mathrm{B}$ after $\mathrm{Ar}$ etching and calculated stoichiometry.

\begin{tabular}{ccccccc}
\hline & Zr (at. \%) & Si (at. \%) & C (at. \%) & O (at. \%) & \multicolumn{2}{c}{ Stoichiometry } \\
\hline A-coating & $3.6^{1}$ & $18.1^{1}$ & $45.4^{1}$ & $32.9^{1}$ & $\mathrm{ZrO}_{1.5}$ & $\mathrm{SiO}_{1.4}$ \\
\hline B-coating & 2.7 & 13.9 & 53.5 & 30.0 & $\mathrm{ZrO}_{1.8}$ & $\mathrm{SiO}_{1.2}$ \\
\hline
\end{tabular}

${ }^{1}$ Data compiled from previous work [13] for comparison.

A-coating
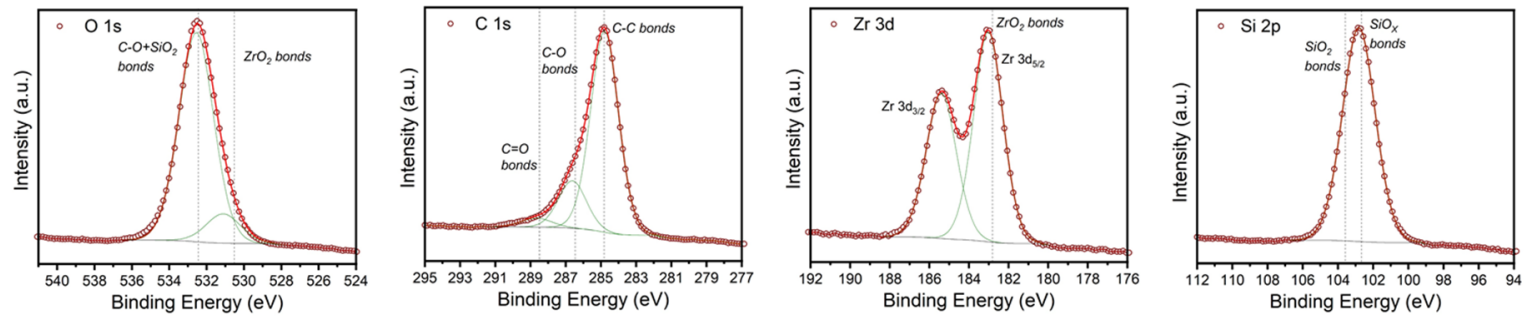

B-coating
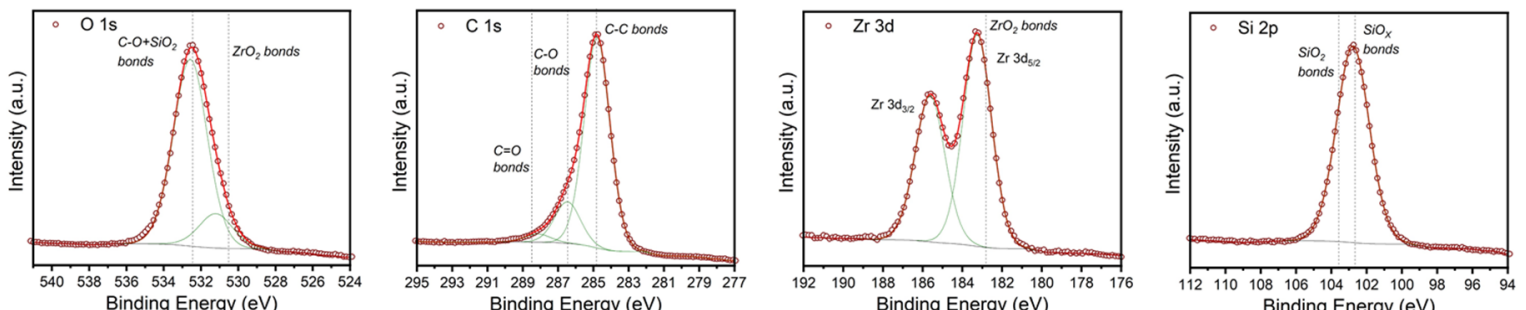

Figure 5. High-resolution XPS spectra of A- and B-coating materials.

Ag NWs were embedded in the Sol A with the aim to decrease surface electrical resistance through the creation of a conductive path across the hybrid coating. For this purpose, Ag NW size was selected in order to provide a high aspect ratio (huge longitudinal dimension compared to diameter) and make the contact between the nanowires highly probable, thus assuring a continuous conductive path with a low concentration of NW.

The surface of the coatings was observed by SEM and two different micrographs are shown in Figure 3. The two images gave evidence that embedded NW emerged out of the coating material, which was considered favorable from the point of view of electrical contact. The difference observed between Figure 3a,b was that NW were not probably homogeneously distributed. Figure 3a showed a single NW emerging from the coating material while some NW agglomerates were also found emerging from the surface, as observed in Figure $3 b$. 


\subsection{Contact Electrical Resistance}

In order to provide antistatic performance, aluminum surfaces must show low contact electrical resistance. One of the main differences between chemical conversion coatings and hybrid sol-gel coatings is the thickness. Through two distinct methods, both technologies grow dielectric coatings based on mixed metal oxides with further organic moieties in the case of sol-gel. However, the corrosion protection provided by an intentionally dense and insulating hybrid sol-gel coating material competes with the low resistivity that it should be offered. Thus, a proper balance of these properties must be envisaged to provide corrosion resistance enhancement and low surface electrical resistance. The aerospace industry usually regards MIL-DTL-81706B standard [15], which details the requirements of the chemical conversion materials for coating aluminum alloys. In a particular case, materials that form corrosion protective coatings by chemical reaction with aluminum alloys are required for aluminum compounds that need low electrical resistance. The contact electrical resistance measurement consists of evaluating the bulk resistivity of a coated aluminum plate 1-mm thick, placed between two polished copper electrodes under a contact pressure of 200 pounds per square inch. Therefore, such method is not focused on measuring the electrical resistance of the coating itself, but that of the coating-material system under pressure. In this system, several factors related to coating-electrode and coating-material interfaces such as coating thickness, coating density, substrate roughness and coating roughness may have a crucial role in the measurement.

As explained, the AlMgSi alloys present different amounts of $\mathrm{Mg}$, $\mathrm{Si}$ and $\mathrm{Cu}$ alloying elements, which results in differences in the susceptibility to corrosion of each alloy. In this work different options have been explored for each alloy in order to obtain the proper tradeoff between corrosion resistance enhancement and low surface electrical resistance. For the protection of AA6082, which contains a high quantity of $\mathrm{Si}$ and is the most susceptible to corrosion, thick and dense coating materials were envisaged. Sol A deposited at 5 and $15 \mathrm{~cm} / \mathrm{min}$ was studied, and two different strategies to prepare denser materials by increasing solid concentration and organic/inorganic ratio were accomplished, thus sols AC and B deposited at 5 and $15 \mathrm{~cm} / \mathrm{min}$. For AA6061, which contains high quantity of $\mathrm{Cu}$ and is usually envisaged for electrical and electronic aerospace applications where low contact electrical resistance is required, different thicknesses of the less dense A-coating were studied. Sol A was deposited at 5,15 and $35 \mathrm{~cm} / \mathrm{min}$ to achieve the tradeoff between corrosion protection and electrical resistance. With the aim to create a conductive path, Ag nanowires were loaded in a low concentration in the A sol-gel matrix and the resulting coatings were studied on the AA6063 alloy.

According to MIL-DTL-81706B standard [15], before exposing plates to NSST, the average of contact electrical resistance measurements shall be not greater than $5000 \mu \Omega$ per square inch, while individual measurements shall not exceed $6000 \mu \Omega$ per square inch. Based on that, mean and individual values of contact electrical resistance for the three alloys are presented in Figure 6. It was not possible to measure the resistance of $\mathrm{AC}_{15}$ - and $\mathrm{B}_{15}$-coatings on $\mathrm{AA} 6082$ because of the insulating nature of the coatings, resulting in open circuit. None of the coatings deposited on AA6082 (with a thickness between 1.6 and $4.4 \mu \mathrm{m}$ as shown in Figures 1 and 2) exhibited electrical resistance mean values below $5000 \mu \Omega$ per square inch. However, the coatings deposited with Sol A on AA6061 (with a thickness between 1.6 and $3.2 \mu \mathrm{m}$, as shown in Figures 1 and 2) presented mean values below $5000 \mu \Omega$ per square inch, although one individual value exceeded $6000 \mu \Omega$ per square inch for the thicker coating system. A remarkable result was that $\mathrm{A}_{5}$ - and $\mathrm{A}_{15}$-coatings provided low contact electrical resistance only if deposited on AA6061 instead of AA6082. In the same direction, $A_{5}$-coating on AA6063 did not provide mean values below $5000 \mu \Omega$ per square inch. The electrical resistivity of these aluminum alloys can vary from 3 to $4 \times 10^{-6} \Omega \cdot \mathrm{cm}$ [14], while the coating material has high electrical resistivity due to its hybrid organo-ceramic nature. Therefore, it is considered that the contact electrical resistance is the result of the measurement method, electrode-coating-metal interfaces and the alloy. It is expected that electrons are likely to find a path when a high pressure is applied on the thinner and less dense coatings. If such coatings, with highly levelling effect, are applied on rough metal surfaces, the path between metal peaks and the electrode is even reduced. In particular, the surface of AA6063 did not 
present peaks, which can stand as the main reason to not meet contact electrical resistance criteria even with such thin coatings. As AA6063 presents low susceptibility to corrosion with neither $\mathrm{Cu}$ content nor Si excess, Ag NW were embedded in the A-coating with good electrical results (Figure 6c). However, a tradeoff with corrosion resistance should be performed (see corrosion results).

According to MIL-DTL-81706B standard [15], contact electrical resistance should be measured again after $168 \mathrm{~h}$ of exposure to NSST. In this case, the average of contact electrical resistance measurements shall be not greater than $10,000 \mu \Omega$ per square inch, while individual measurements shall not exceed $12,000 \mu \Omega$ per square inch. Contact electrical resistance after NSST exposure was measured only on A-coating deposited on the three alloys (Figure $6 \mathrm{~d}$ ). It can be observed that the contact electrical resistance on AA6061 and AA6063 met all the standard's criteria. However, coated AA6082 after exposure did not exhibit an average value below 10,000 $\mu \Omega$ per square inch.

a)

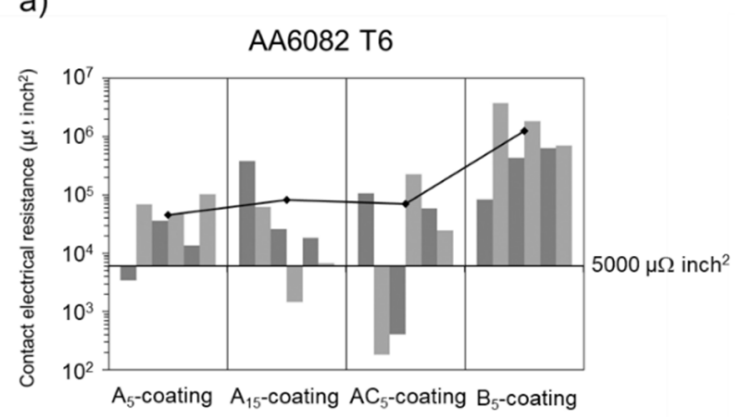

c)

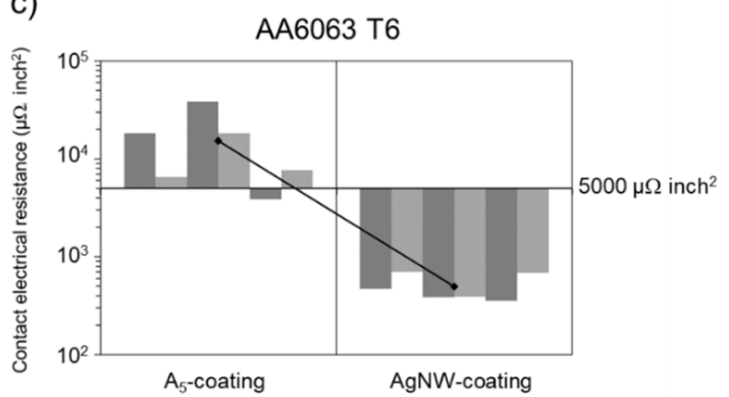

b)

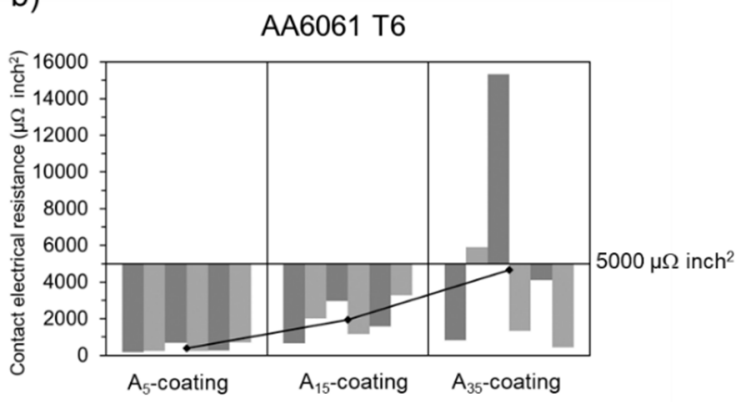

d)

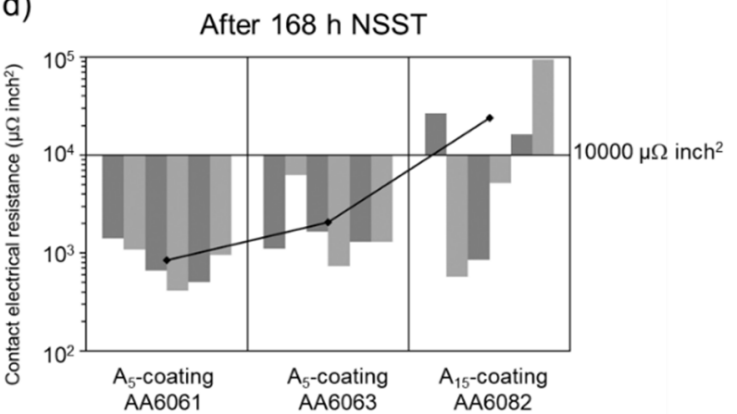

Figure 6. Contact electrical resistance measured on three AlSiMg alloys coated with the investigated sols $(\mathbf{a}-\mathbf{c})$ before and $(\mathbf{d})$ after $168 \mathrm{~h}$ of exposure to NSST.

\subsection{Electrochemical Characterization}

Impedance measurements were recorded during immersion in $3.5 \% \mathrm{NaCl}$ solution at $0,2,5,24,48$ and $72 \mathrm{~h}$. Bode frequency plots corresponding to coated and uncoated AlMgSi alloys at initial and final times of immersion are depicted in Figure 7. Based on the high repeatability of the measurements, the plots corresponding to only one repetition are presented. AA6082, with a high 1\% wt $\mathrm{Si}$ in their composition, has the highest susceptibility to corrosion. High concentrated sols AC and B, the latter with high organic/inorganic ratio, were deposited at $15 \mathrm{~cm} / \mathrm{min}$ and studied in parallel with Sol A for comparison. AA6061 is the alloy with a better tradeoff between corrosion susceptibility, mechanical and electrical properties. This alloy was coated with low concentrated Sol A at 5, 15 and $35 \mathrm{~cm} / \mathrm{min}$ with the aim to study the coating thickness effect on barrier properties. AA6063 presents low corrosion susceptibility, and it was coated with Sol A at $5 \mathrm{~cm} / \mathrm{min}$. Effect of Ag NW incorporation in Sol A was studied on this alloy as it provided the required conductive electrical path to reach the requested low contact electrical resistance.

Differences between the coatings applied on AA6082 were found from the initial stages. The impedance of all the coated AA6082 substrates presented a parallel combination of the coating capacitance, over a wide frequency range, and the pore resistance. The impedance modulus at low 
frequencies reached $\sim 2 \times 10^{6}, \sim 1 \times 10^{7}$ and $\sim 1 \times 10^{8} \mathrm{ohm} \cdot \mathrm{cm}^{2}$ for $\mathrm{A}_{15^{-}}, \mathrm{AC}_{15^{-}}$and $\mathrm{B}_{15^{-} \text {-coatings, }}$ respectively. The boundary where the capacitive region transforms in a resistive region at phase angle about $45^{\circ}$ is known as breakpoint at low frequency and it can be used to evaluate and rank the performance of coatings [22]. It is related with the defect area, which is lower as breakpoint emerges at lower frequencies. In particular, it was found around $7 \mathrm{~Hz}$ for $\mathrm{A}_{15}$-coating, around $4 \mathrm{~Hz}$ for $\mathrm{AC}_{15}$-coating and around $0.4 \mathrm{~Hz}$ for $\mathrm{B}_{15}$-coating. The highest capacitance, which is related with a low dielectric constant, was observed for $\mathrm{B}_{15}$-coating, indicating a higher barrier effect against water uptake.

The capacitive behavior of all coatings dropped with time evolution, although at different rates, related to the incorporation of polar molecules, which increases the dielectric constant of the coatings. In fact, $\mathrm{B}_{15}$-coating maintained the breakpoint at $1 \mathrm{~Hz}$ while $\mathrm{A}_{15}$ - and $\mathrm{AC}_{15}$-coatings presented new capacitance and resistance behavior associated to defect-containing coatings. Therefore $\mathrm{B}_{15}$-coating showed a capacitive behavior stable with time and therefore a low water uptake, related to the high density of the coating.
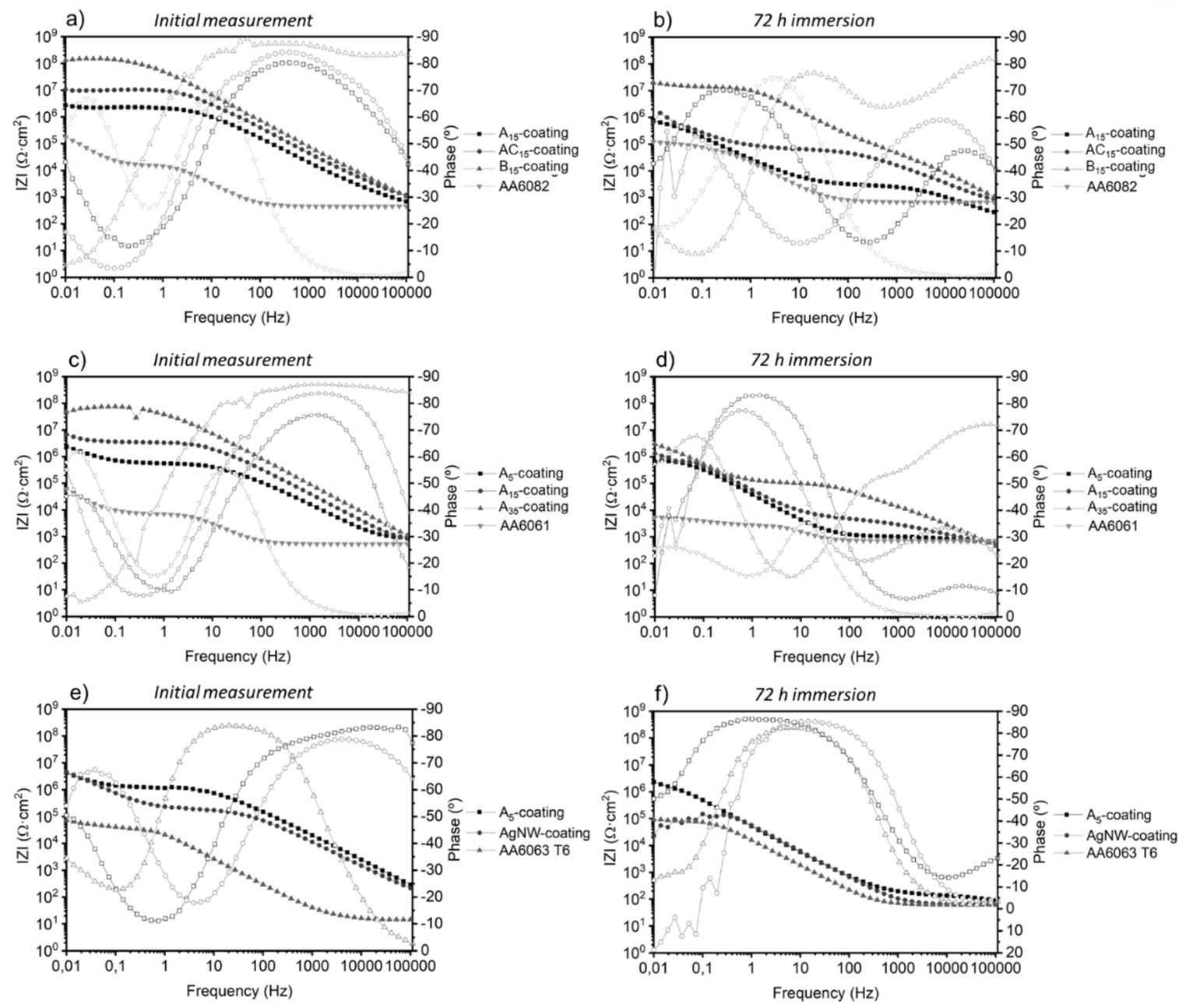

Figure 7. EIS Bode modulus and phase angle plots obtained for AA6082 (a,b), AA6061 (c,d) and AA6063 $(\mathbf{e}, \mathbf{f})$ uncoated and coated with studied sols at initial time $(\mathbf{a}, \mathbf{c}, \mathbf{e})$ and after $72 \mathrm{~h}(\mathbf{b}, \mathbf{d}, \mathbf{f})$ of immersion in $3.5 \% \mathrm{NaCl}$ solution.

The alloy AA6061 was treated only with Sol A deposited at different withdrawal rates, resulting in coatings of the same material but different coating thickness. The impedance modulus at low frequencies reached $\sim 2 \times 10^{6}, \sim 6 \times 10^{6}$ and $\sim 4 \times 10^{7} \mathrm{ohm} \cdot \mathrm{cm}^{2}$ for $\mathrm{A}_{5-}, \mathrm{A}_{15^{-}}$and $\mathrm{A}_{35}$-coatings, respectively. The curves revealed a parallel combination of the coating capacitance over a wide frequency range, and the pore resistance. The capacitive behavior of the thicker $\mathrm{A}_{35}$-coating was highly noticeable 
showing a phase angle of $-90^{\circ}$ from high frequencies up to the breakpoint at $1 \mathrm{~Hz}$, whereas breakpoint appeared at higher frequencies, 20 and $10 \mathrm{~Hz}$ for $\mathrm{A}_{5}$-coating and $\mathrm{A}_{15}$-coating, respectively.

In this case, the capacitive behavior dropped with time at a similar rate for all the coatings since they all had identic dielectric constant. Although the thicker $\mathrm{A}_{35}$-coating had shown a high capacitive performance, the water absorbed by this material made not possible to maintain the barrier effect in contrast to $\mathrm{B}_{15}$-coating applied on AA6082.

A similar behavior was found for the thin $\mathrm{A}_{5}$-coating deposited on AA6063. However, because of the low corrosion susceptibility of these Mg-Si balanced alloys, the lower concentrated sol deposited with the lower thickness was enough to provide protection since the appearance of exposed area after test did not presented corrosion products.

Concerning AgNW-coating on AA6063, the EIS results were not conclusive, since a high scattering of data was found, accompanied by the emergence of pits and corroded areas. Although works with the incorporation of this kind of material have not been found, several studies have used conductive polymers based coatings to obtain antistatic coatings on AlMgSi alloys, such as polyaniline and polypyrrole on AA6061 [23,24] and pyrrole-based silane coatings on AA6082 [25,26]. In a similar way, Martins et al. $[23,24]$ concluded that the coated AA6061 presented in all cases lower corrosion resistance than the bare metal, and pitting corrosion.

Therefore, it is concluded that in this kind of hybrid coatings, the incorporation of a conductive path along an insulating coating is not compatible with the corrosion protection, even on $\mathrm{Al}$ alloys with low susceptibility to corrosion.

\subsection{Durability Assessment}

Different aging tests were performed to assess the corrosion performance of the three AlMgSi alloys under study. NSST according to MIL-DTL-81706B [15] is commonly regarded by the aerospace industry as the most aggressive corrosion test for qualification of materials. Neutral salt spray exposure after thermal cycling was used in this work to assess the coated aluminum alloys ability to withstand induced thermal stress. The damp heat exposure test, with milder conditions, is also required by the space industry.

Representative photographs and SEM images of AA6082 plates coated with sols A, AC and B at $15 \mathrm{~cm} / \mathrm{min}$ after $168 \mathrm{~h}$ of exposure in NSST are shown in Figure 8. Although not visible in front-view images of the tested surfaces (Figure 8a-c), AA6082 coated with Sol A displayed pits along the surface (Figure $8 \mathrm{~d}$ ), starting as black grains along the substrate rolling direction. Corrosion products drained from those pits were present, as observed in the SEM image in Figure $8 \mathrm{~g}$. The $\mathrm{AC}_{15}$-coating, with higher thickness, provided good corrosion protection as observed in Figure 8b,e, where no damage on the surface was observed. Only some defects attributed to coating damage were observed in SEM analysis as presented in Figure $8 \mathrm{~h}$. On the other hand, the best corrosion performance and appearance after test was displayed by the $\mathrm{B}_{15}$-coating. The higher organic/inorganic ratio in the composition allowed to avoid any crack failure provoked by stress during the test. 

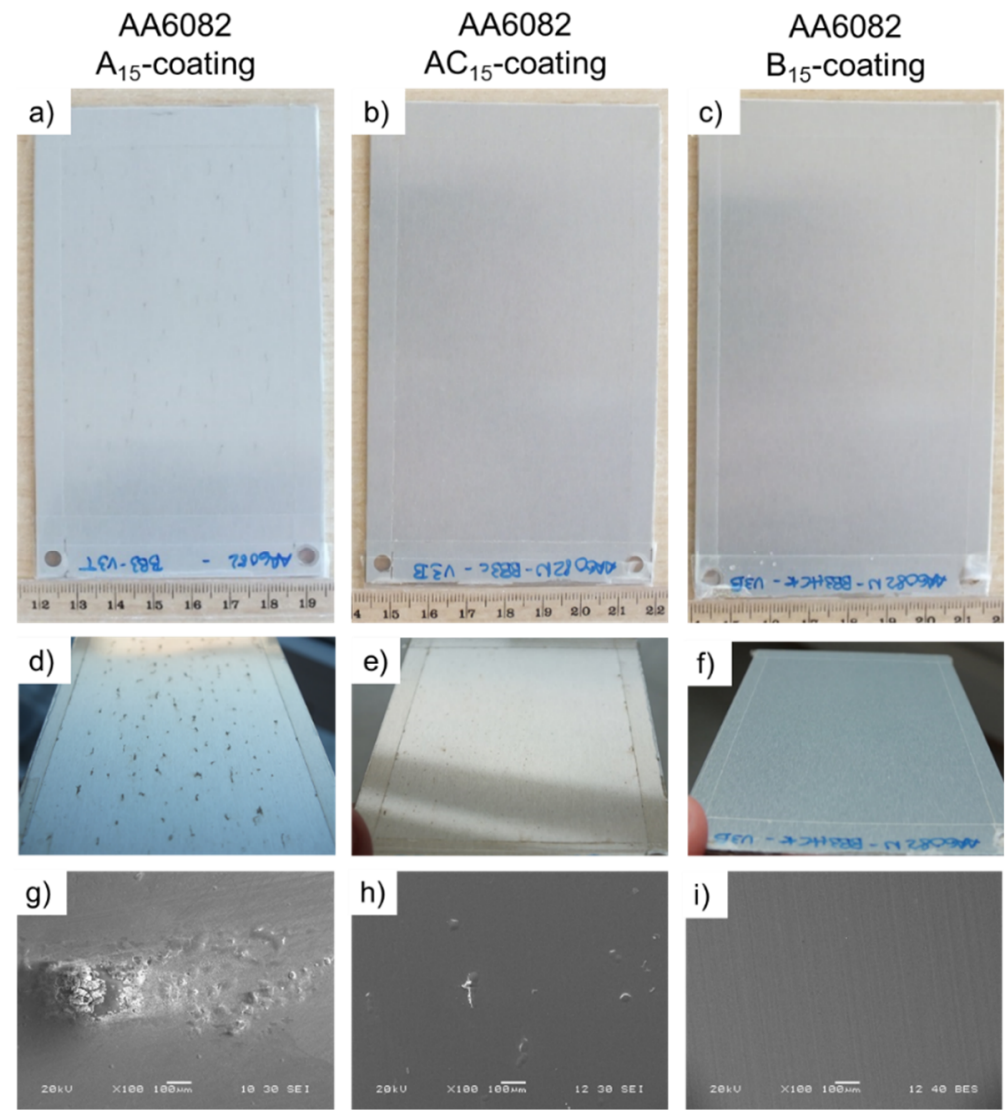

Figure 8. Straight and tilted photographs and SEM images of AA6082 T6 coated with Sol A (a,d,g), Sol $\mathrm{B}(\mathbf{b}, \mathbf{e}, \mathbf{h})$ and Sol AC $(\mathbf{c}, \mathbf{f}, \mathbf{i})$ at $15 \mathrm{~cm} / \mathrm{min}$ after $168 \mathrm{~h}$ of exposure in NSST.

Concerning AA6061 and AA6063, with lower corrosion susceptibility, the thinnest $\mathrm{A}_{5}$-coating provided enough protection after $168 \mathrm{~h}$ of NSST, as requested in MIL-DTL-81706B standard [15] (Figure 9a,b). However, as predicted by EIS measurements, the AgNW-coating did not provide corrosion protection for AA6063. This corroborates further that the conductive path created by the $\mathrm{Ag}$ nanowires is incompatible with the anticorrosion property provided by a hybrid coating whose protective strategy is based on metal insulation from aggressive environment.
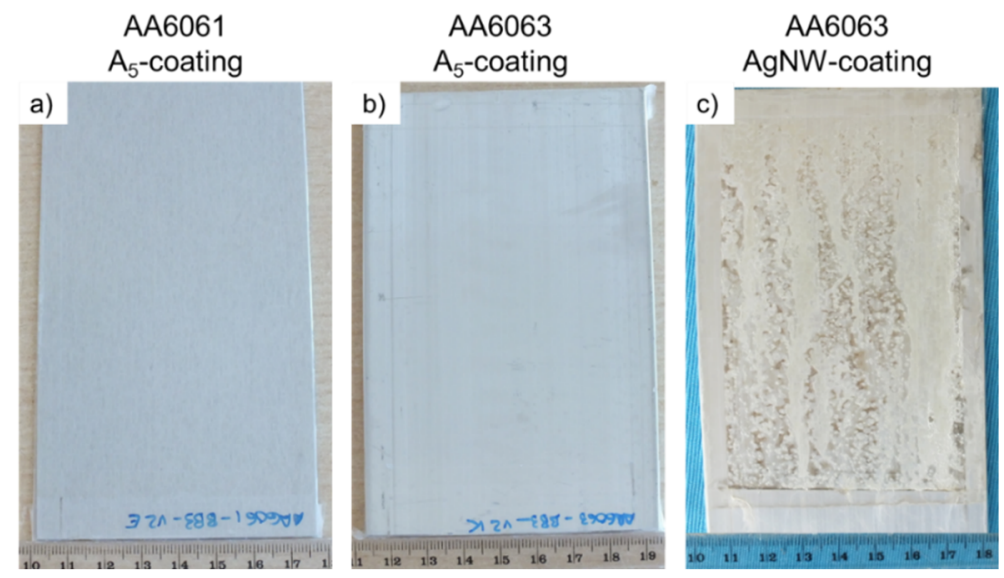

Figure 9. Representative photographs of (a) AA6061 T6 coated with Sol A; AA6063 T6 coated with (b) Sol A, and (c) Sol A-AgNW at $5 \mathrm{~cm} / \mathrm{min}$ after $168 \mathrm{~h}$ of exposure in NSST. 
Cr VI and Cr III conversion coatings on AA6063 and AA6082 were also tested for comparison, as they are still currently used for aerospace applications. These coatings provided corrosion protection for the studied alloys after $168 \mathrm{~h}$ in NSST. However, different protection behavior was observed after thermal cycling tests (Figure 10). The expansion and contraction of the samples as they are heated up and cooled down did not cause fatigue or adhesion failure of the coatings due to thermal shock. However, corrosion protection performance was altered. AA6082 coated with Cr VI and Cr III conversion coatings presented corrosion products after $24 \mathrm{~h}$ of exposure in NSST following thermal cycling, in contrast to $\mathrm{A}_{15}$-coating which provided corrosion protection and a homogeneous surface as observed in the photographs showed in Figure 10. In the same way, Cr VI and Cr III conversion coatings did not displayed proper corrosion protection on AA6063 after $168 \mathrm{~h}$ of NSST following thermal cycling, in contrast to $A_{5}$-coating, which provided unaffected aluminum surface after this time of exposure.

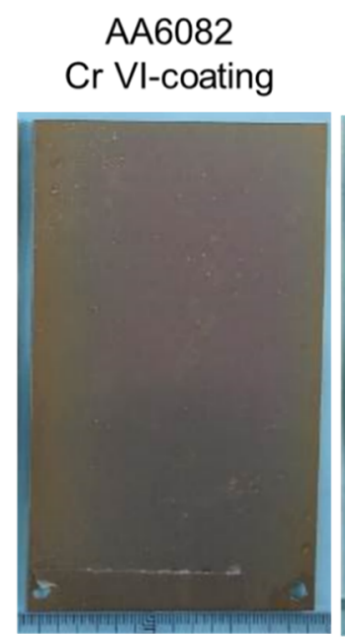

AA6063

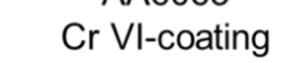

AA6082
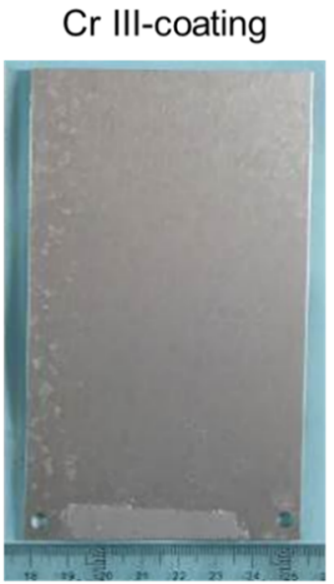

AA6063

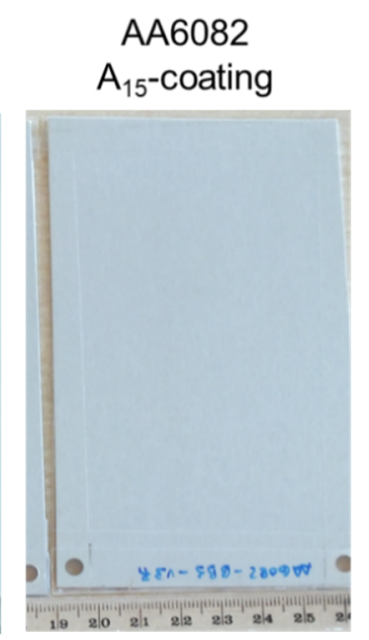

AA6063

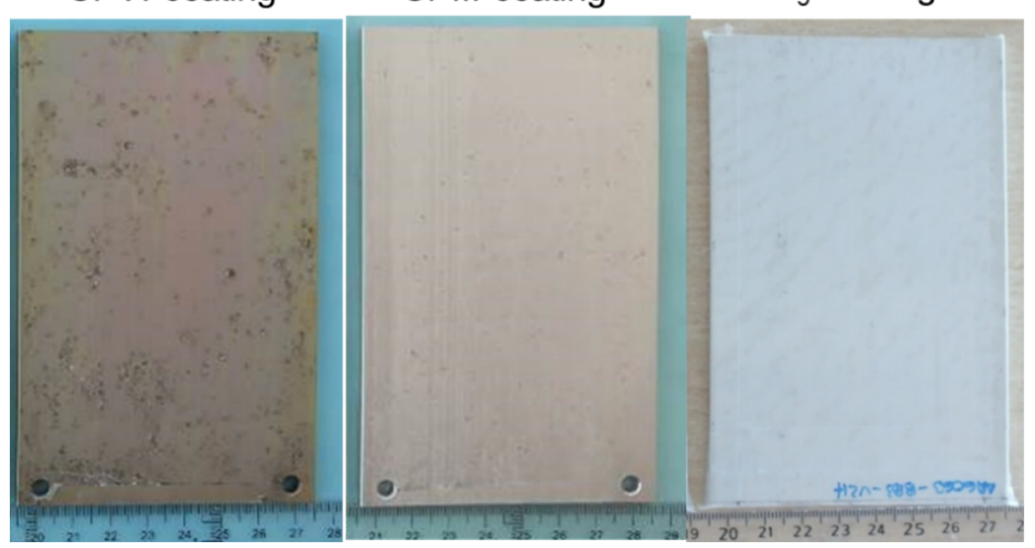

Figure 10. Representative photographs of AA6082 T6 plates coated with Cr VI, Cr III and A coatings after thermal cycling and $24 \mathrm{~h}$ of exposure to NSST (above) and same coatings on AA6063 T6 after thermal cycling and $168 \mathrm{~h}$ of exposure to NSST (below).

Considering exposure to milder conditions (DHT), none of the AA6082 and AA6063 plates coated with Sol A, and conversion coatings based on Cr VI and Cr III showed any surface failure after damp heat exposure during $336 \mathrm{~h}$, as observed in Figure 11. 


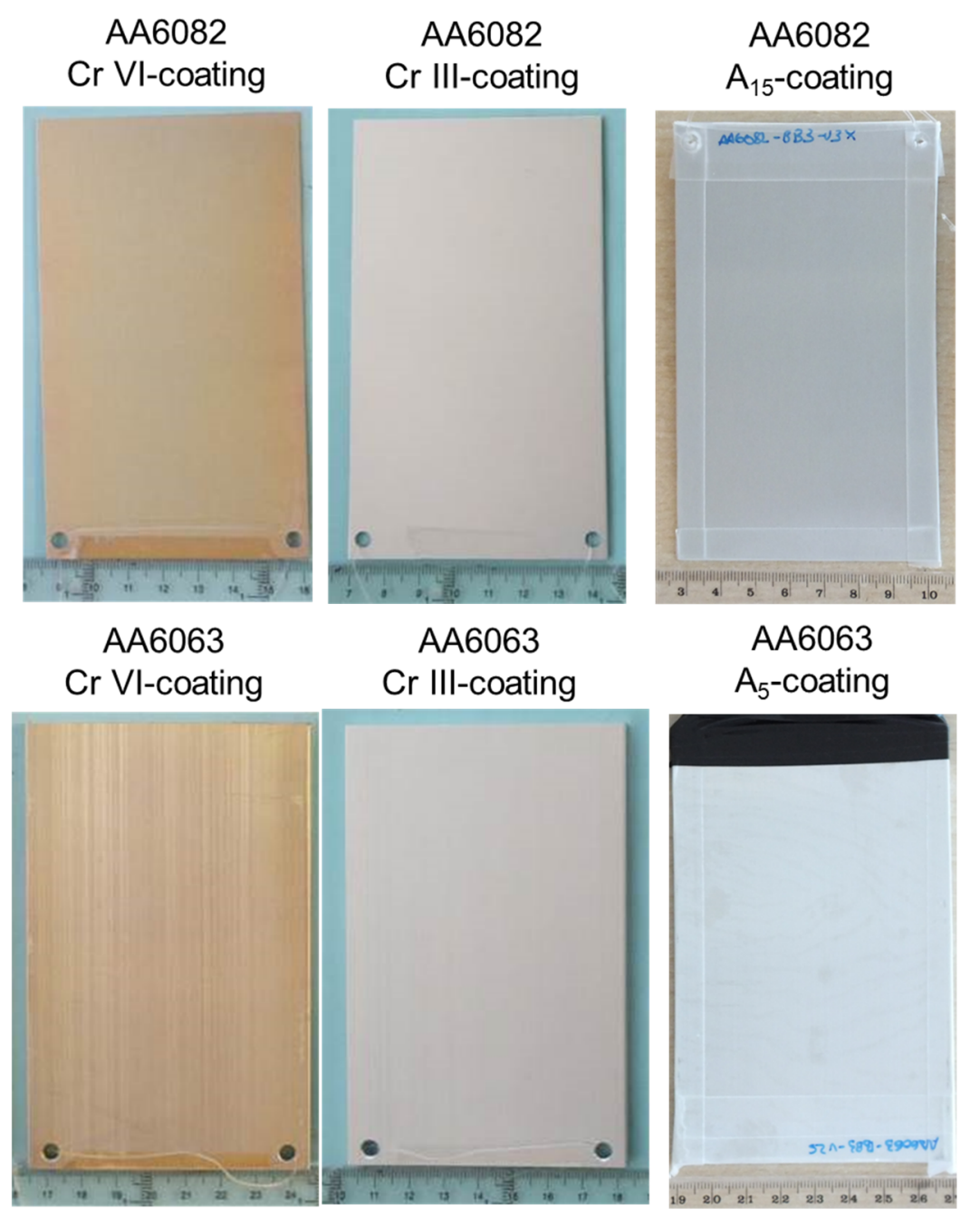

Figure 11. Representative photographs of AA6082 T6 (above) and AA6063 T6 (below) plates coated with Cr VI, Cr III and A coatings after $336 \mathrm{~h}$ of exposure to DHT.

\subsection{Vacuum-Induced Outgassing}

Assessment of outgassing of the coatings derived from the three proposed sol formulations was performed to check the suitability for space applications. The sublimation test described in ECSS-Q-ST-70-02C [16] served to quantify the mass loss of coatings due to vacuum conditioning at elevated temperature as a function of time. As explained above, the coatings undergo a $24-\mathrm{h}$ pre-conditioning step at $22{ }^{\circ} \mathrm{C}$ and $55 \% \mathrm{RH}$, during which they absorb moisture. Then, the vacuum thermal test is performed during $24 \mathrm{~h}$ at $125^{\circ} \mathrm{C}$ and $<10^{-4} \mathrm{~Pa}$. The difference in weight of the coating before and after this step corresponds to the total mass loss (TML) parameter. During this time, condensed matter is collected in cooled plates. The mass gain of collectors relative to initial coating mass is designated as collected volatile condensable material (CVCM). After a post-conditioning step of $24 \mathrm{~h}$ at $22{ }^{\circ} \mathrm{C}$ and $55 \% \mathrm{RH}$, during which the coatings are allowed to recover the absorbed moisture, they are weighed again, to calculate moisture uptake, designated as water vapor regained (WVR). Then, recovered mass loss (RML) is the difference between TML and WVR and corresponds to the total mass loss of the specimen itself without the absorbed water.

As observed in Table 5, the TML of coatings was between 3.5\% and 5.5\% depending on the coating formulation. The lowest value corresponded to the coating with the highest organic content, thus $\mathrm{B}_{15}$-coating. However, this value was highly influenced by the moisture uptake, which indeed was related to the density of each coating. In addition, the organic/inorganic ratio played a crucial role in 
the density of the coating, more than equivalent solid concentration, as concluded in the EIS analysis. The $\mathrm{B}_{15}$-coating with highest density, absorbed $1.76 \%$ of moisture. The $\mathrm{AC}_{15}$-coating with the lowest density, absorbed $4.165 \%$ of moisture. Consistently, $\mathrm{A}_{15}$-coating with slightly higher value of density, absorbed less quantity of moisture, 3.753\%. Meanwhile the difference between Sol A and Sol AC is the equivalent solid concentration, the coatings derived from those sols at similar withdrawal rate differ on the thickness, being 2.4 and $4 \mu \mathrm{m}$ when deposited at $15 \mathrm{~cm} / \mathrm{min}$, respectively. This affected the coating densification during the curing step. However, the lower propanol quantity lead to attain a lower inherent mass loss with an RML of $1.318 \%$. On the contrary, $\mathrm{B}_{15}$-coating, which showed the lowest moisture uptake, presented the highest intrinsic mass loss induced by vacuum, RML reaching $1.791 \%$, as well as extremely high quantity of volatile material condensed on cool collector. In fact, CVCM reached up to $0.3 \%$, in contrast to the low values registered from $\mathrm{A}_{15}$ - and $\mathrm{AC}_{15}$-coatings, being $<0.01 \%$. The condensed material from $\mathrm{B}_{15}$-coating was mainly bisphenol A according to FTIR analysis.

Table 5. Outgassing parameters of coatings deposited at $15 \mathrm{~cm} / \mathrm{min}$ from the sols A, AC and B.

\begin{tabular}{ccccccc}
\hline & $\mathbf{m g} / \mathbf{c m}^{\mathbf{2}}$ & $\mathbf{g} / \mathbf{c m}^{\mathbf{3}}$ & TML (\%) & RML (\%) & WVR (\%) & CVCM (\%) \\
\hline $\mathrm{A}_{15}$-coating & 0.54 & 1.13 & $5.157 \pm 0.392$ & $1.404 \pm 0.033$ & $3.753 \pm 0.455$ & $0.009 \pm 0.002$ \\
$\mathrm{AC}_{15}$-coating & 0.80 & 1.03 & $5.483 \pm 0.400$ & $1.318 \pm 0.153$ & $4.165 \pm 0.495$ & $0.006 \pm 0.003$ \\
$\mathrm{~B}_{15}$-coating & 1.35 & 1.53 & $3.551 \pm 0.035$ & $1.791 \pm 0.037$ & $1.760 \pm 0.059$ & $0.303 \pm 0.132$ \\
\hline
\end{tabular}

The outgassing requirements described in ECSS-Q-ST-70-02C standard [16] are RML $<1.0 \%$ and CVCM $<0.10 \%$. Meanwhile, materials with RML $<1.0 \%$ and TML $>1.0 \%$ are considered acceptable should they meet several conditions mentioned in the standard. Therefore, only $\mathrm{A}_{15}$ - and $\mathrm{AC}_{15}$-coatings fulfil the CVCM $<0.10 \%$ requirement, while RML should be slightly reduced since WVR only affects only to some specific applications. As an example, longer thermal treatment would promote further desorption and release of unreacted species entrapped or weakly bonded to coating network, which are prone to abandon it in vacuum conditions.

\section{Conclusions}

The suitability of hybrid sol-gel coatings applied on three different AlMgSi alloys for aerospace application was assessed. Sol-gel formulations were based on the combination of inorganic precursor of silica (TEOS) and zirconia (TPOZ) and organic precursor (BPA) interconnected to the matrix through Si epoxy functionalized-alkoxide (GPTMS). The effect of equivalent solid content, organic/inorganic ratio and withdrawal rates during coating deposition was assessed. These parameters have a crucial influence on sol viscosity, coating thickness and roughness, which were found to be directly related to contact electrical resistance, corrosion protection, barrier effect, water uptake, durability and outgassing properties.

Among the assessed AlMgSi alloys, AA6063, with balanced amounts of $\mathrm{Mg}$ and $\mathrm{Si}$, presents the lowest mechanical properties and the lowest susceptibility to corrosion. The thin $\mathrm{A}_{5}$-coating deposited from the low concentrated Sol A was enough to protect it against corrosion in neutral salt spray test, thermal shock during thermal cycling and damp heat exposure, in spite of the tendency to water uptake revealed by the results of both EIS performed in immersion in sodium chloride solution and outgassing test (post-conditioning step). Because of the particular topography of its surface, the contact electrical resistance of the coated AA6063 did not meet the criteria requested by aerospace standards. A low load of Ag NW in the coating was enough to provide a conductive path and attain low contact electrical resistance, however this incorporation had a negative effect on the corrosion protection properties.

AA6061, with balanced amounts of $\mathrm{Mg}$ and $\mathrm{Si}$, presented intermediate mechanical properties thanks to the $\mathrm{Cu}$ alloying element. In a similar way to AA6063, the thin $\mathrm{A}_{5}$-coating provided the required corrosion protection, as well as low contact electrical resistance before and after exposure to NSST, with better results in terms of recovered mass loss obtained in the outgassing test, that should be slightly further optimized. 
In the case of unbalanced AA6082, the excess of Si confers the highest mechanical properties among the studied alloys, accompanied by a higher susceptibility to corrosion resistance. Two different strategies were followed to obtain thicker and denser coatings. The Sol B with higher organic/inorganic ratio provided outstanding corrosion protection to this alloy, showing a long stability along time. However, this higher organic content drove to the worst results under vacuum-induced outgassing. Furthermore, high contact electrical resistance values were obtained for all the tested coatings deposited on this alloy.

In the light of these outcomes, the most complete solution was found for AA6061, which showed the better tradeoff between corrosion susceptibility, mechanical and electrical properties.

\section{Patents}

Inventors: Cecilia Agustín Sáenz, Patricia Santa Coloma Mozo, Eider Martín Ugarte, Marta Brizuela Parra; Applicant: Tecnalia. A hybrid sol-gel corrosion-resistant coating composition. WO2018073186 A1 (26 April 2018).

Author Contributions: C.A.-S.: Conceptualization, Investigation, Visualization, Methodology, Analysis and Writing-Original draft; P.S.C.: Conceptualization, Investigation and Methodology of ageing tests and electrical properties measurement; F.J.F.-C.: Conceptualization and Methodology of electrical properties measurement; F.B.: Conceptualization of outgassing test and Writing-Reviewing and editing; M.B.: Funding acquisition and Project administration. All authors have read and agreed to the published version of the manuscript.

Funding: This work has received funding from the European Union's Horizon 2020 Research and Innovation Programme within the project PEGASUS under Grant Agreement no. 640143; from the European Space Agency within ESA ITI Programme under contract number 4000124218 (IRUCOAT4SPACE project) and from the Basque Government through FRONTIERS IV project (ELKARTEK 2018, KK-2018/00108).

Acknowledgments: The authors thank the Spanish National Institute for Aerospace Technology (INTA) for outgassing measurements.

Conflicts of Interest: The authors declare no conflict of interest.

\section{References}

1. Mondolfo, L.F. Aluminum Alloys: Structure and Properties; Butterworths \& Co. Ltd.: London, UK, 1976.

2. Larsen, M.H.; Walmsley, J.C.; Lunder, O.; Nisancioglu, K. Effect of excess silicon and small copper content on intergranular corrosion of 6000-Series aluminum alloys. J. Electrochem. Soc. 2010, 157, C61. [CrossRef]

3. Totten, G.E.; MacKenzie, D.S. Handbook of Aluminum; Marcel Dekker Inc.: New York, NY, USA, 2003; ISBN 9780203912591.

4. Kairy, S.K.; Alam, T.; Rometsch, P.A.; Davies, C.H.J.; Banerjee, R.; Birbilis, N. Understanding the origins of intergranular corrosion in copper-containing Al-Mg-Si alloys. Metall. Mater. Trans. A Phys. Metall. Mater. Sci. 2016, 47, 985-989. [CrossRef]

5. Svenningsen, G.; Lein, J.E.; Bjørgum, A.; Nordlien, J.H.; Yu, Y.; Nisancioglu, K. Effect of low copper content and heat treatment on intergranular corrosion of model AlMgSi alloys. Corros. Sci. 2006, 48, 226-242. [CrossRef]

6. He, C.; Li, R.; Meng, X.; Lü, S.; Xie, L.; Ma, G.; Wang, J. Effect of Quenching Condition on Corrosion Behavior of 6063 Al Alloy. Int. Conf. Manuf. Sci. Eng. 2015, 1873-1876.

7. Nazeer, A.A.; Madkour, M. Potential use of smart coatings for corrosion protection of metals and alloys: A review. J. Mol. Liq. 2018, 253, 11-22. [CrossRef]

8. Santa Coloma, P.; Izagirre, U.; Belaustegi, Y.; Jorcin, J.B.; Cano, F.J; Lapeña, N. Chromium-free conversion coatings based on inorganic salts $(\mathrm{Zr} / \mathrm{Ti} / \mathrm{Mn} / \mathrm{Mo})$ for aluminum alloys used in aircraft applications. Appl. Surf. Sci. 2015, 345, 24-35. [CrossRef]

9. Hoebbel, D.; Nacken, M.; Schmidt,H. A NMR study on the hydrolysis, condensation and epoxide ring-opening reaction in sols and gels of the system glycidoxypropyltrimethoxysilane-water-titaniumtetraethoxide. J. Sol-Gel Sci. Technol. 1998, 12, 169-179. [CrossRef]

10. Yadav, R.; Tirumali, M.; Wang, X.; Naebe, M.; Kandasubramanian, B. Polymer composite for antistatic application in aerospace. Def. Technol. 2020, 16, 107-118. [CrossRef] 
11. Larsson, A. The interaction between a lightning flash and an aircraft in flight. C. R. Phys. 2002, 3, 1423-1444. [CrossRef]

12. Gagné, M.; Therriault, D. Lightning strike protection of composites. Prog. Aerosp. Sci. 2014, 64, 1-16. [CrossRef]

13. Agustín-Sáenz, C.; Martín-Ugarte, E.; Jorcin, J.B.; Imbuluzqueta, G.; Santa Coloma, P.; Izagirre-Etxeberria, U. Effect of organic precursor in hybrid sol-gel coatings for corrosion protection and the application on hot dip galvanised steel. J. Sol-Gel Sci. Technol. 2019, 89, 264-283. [CrossRef]

14. Verma, S.; Gupta, M.; Misra, J.P. Friction stir welding of aerospace materials: A state of art review. In Chapter 13 in DAAAM International Scientific Book 2016; Katalinic, B., Ed.; DAAAM International: Vienna, Austria, 2016; pp. 135-150, ISBN 978-3-902734-09-9.

15. MIL-DTL-81706B. Chemical Conversion Materials for Coating Aluminium and Aluminium Alloys; Naval Air Warfare Center Aircraft Division: Lakehurst, NJ, USA, 2006.

16. ECSS-Q-ST-70-02C. Space Product Assurance, Thermal Vacuum Outgassing Test for the Screening of Space Materials; ECSS Secretariat ESA-ESTEC, Requirements \& Standards Division: Noordwijk, The Netherlands, 2008.

17. MIL-DTL-5541F. Chemical Conversion Coatings on Aluminum and Aluminum Alloys; Naval Air Warfare Center Aircraft Division: Lakehurst, NJ, USA, 2006.

18. ISO 4288. Geometrical Product Specifications (GPS)—Surface Texture: Profile Method-Rules and Procedures for the Assessment of Surface Texture; International Organization for Standardization: Geneva, Switzerland, 1996.

19. ECSS-Q-ST-70-04C. Thermal Testing for the Evaluation of Space Materials, Processes, Mechanical Parts and Assemblies; ECSS Secretariat ESA-ESTEC, Requirements \& Standards Division: Noordwijk, The Netherlands, 2008.

20. Scriven, L. Physics and applications of dip coating and spin coating. Mater. Res. Soc. Symp. Proc. 1988, 121, 717-729. [CrossRef]

21. Faustini, M.; Louis, B.; Albouy, P.A.; Kuemmel, M.; Grosso, D. Preparation of sol-gel films by dip-coating in extreme conditions. J. Phys. Chem. C 2010, 114, 7637-7645. [CrossRef]

22. Feng, Z.; Frankel, G.S. Evaluation of coated Al alloy using the breakpoint frequency method. Electrochim. Acta 2016, 187, 605-615. [CrossRef]

23. Martins, N.C.T.; Moura e Silva, T.; Montemor, M.F.; Fernandes, J.C.S.; Ferreira, M.G.S. Electrodeposition and characterization of polypyrrole films on aluminium alloy 6061-T6. Electrochim. Acta 2008, 53, 4754-4763. [CrossRef]

24. Martins, N.C.T.; Moura e Silva, T.; Montemor, M.F.; Fernandes, J.C.S.; Ferreira, M.G.S. Polyaniline coatings on aluminium alloy 6061-T6: Electrosynthesis and characterization. Electrochim. Acta 2010, 55, 3580-3588. [CrossRef]

25. Trueba, M.; Trasatti, S.P. Pyrrole-based silane primer for corrosion protection of commercial Al alloys. Part I: Synthesis and spectroscopic characterization. Prog. Org. Coat. 2009, 66, 254-264. [CrossRef]

26. Trueba, M.; Trasatti, S.P. Pyrrole-based silane primer for corrosion protection of commercial Al alloys. Part II. Corrosion performance in neutral $\mathrm{NaCl}$ solution. Prog. Org. Coat. 2009, 66, 265-275. [CrossRef]

(C) 2020 by the authors. Licensee MDPI, Basel, Switzerland. This article is an open access article distributed under the terms and conditions of the Creative Commons Attribution (CC BY) license (http://creativecommons.org/licenses/by/4.0/). 